ROBERT D. WILLIG

Department of Justice

\title{
Merger Analysis, Industrial Organization Theory, and Merger Guidelines
}

The LeAdership of the Antitrust Division of the U.S. Department of Justice has, over the past two years, emphasized that the department's 1984 merger guidelines are a sound prescription for horizontal merger enforcement, that as a matter of policy they are being applied in enforcement decisionmaking, and that there may be a need for "clarification and fine-tuning" of the guidelines. ${ }^{1}$ This paper examines some facets of the antitrust analysis of horizontal mergers in the light shed by industrial organization (IO) theory, in order to stimulate discussion of some possible directions for fine-tuning and clarification of the guidelines. I focus on the possible anticompetitive effects of horizontal mergers and the role of potential entry in merger analysis. However, to set the context for these subjects, it will be helpful first to sketch the nature of the merger guidelines.

Except where specifically noted, the views expressed in this paper do not necessarily reflect those of the Department of Justice. Robert D. Willig is on leave from Princeton University. He gratefully acknowledges stimulating conversations with and helpful comments from Jonathan Baker, Paul Denis, Jim Langenfeld, Janusz Ordover, Steve Salop, Marius Schwartz, Dave Simpson, and Greg Werden. They should not be held accountable for the outcome.

1. See Rill (1990b); and U.S. Department of Justice (1984), hereafter cited as Guidelines. 


\section{The 1984 Merger Guidelines}

Under section 7 of the Clayton Act, a merger is prohibited if its effect "may be substantially to lessen competition, or to tend to create a monopoly." The purpose of the merger guidelines is, for the sake of the predictability and accuracy of the enforcement program, to indicate the circumstances in which the Department of Justice is likely to challenge mergers (and acquisitions) under section $7 .^{2}$ The 1984 guidelines, and the 1982 guidelines from which they evolved, are dramatic departures from the previous guidelines published in 1968. The 1968 guidelines relied almost exclusively on measures of concentration and provided little precise guidance on how to define the relevant market, the universe over which concentration would be measured. In contrast, the 1982 and 1984 guidelines articulate a conceptually rich framework for merger analysis "that is largely consistent with the perspectives of theoretical economics. Indeed, the noteworthy intellectual feat of the guidelines' authors is the creation of a forensically useful framework that embodies much of the best available economic learning." 3 These guidelines aim squarely at predicting with economic tools whether a merger will create or enhance market power, or facilitate its exercise, while avoiding unnecessary interference with mergers that are competitively beneficial or neutral. ${ }^{4}$

The analytic process defined by the 1984 guidelines for horizontal mergers can be described as a series of discrete steps: ${ }^{5}$

-Delineation of the relevant product and geographic market;

-Identification of firms included as participants in the relevant market;

2. Essentially the same standards are also applied to challenges of mergers and acquisitions under section 1 of the Sherman Act.

3. Ordover and Willig (1983).

4. According to the 1984 guidelines, section 1.0 "This ability of one or more firms profitably to maintain prices above competitive levels for a significant period of time is termed 'market power.' Sellers with market power also may eliminate rivalry on variables other than price." In addition, market power may also refer to analogous monopsony effects.

5. The sketch that follows is very incomplete for the sake of brevity. See Werden (1983) or Salop and others (1987) for a more complete interpretive treatment, or the guidelines themselves. 
-Calculation and interpretation of market shares and concentration;

-Assessing ease of entry;

-Consideration of other factors; and

-Assessing efficiencies.

Each step has its own complexities, subtleties, and relationships to industrial organization theory. A basic understanding of many of the steps is necessary to appreciate the economic rationality of the guidelines' analytic framework and the issues discussed later regarding finetuning and clarification. Delineation of the relevant market is the most novel and central portion of the framework.

The relevant market is delineated by means of an analysis of what set of products (at associated locations) has sufficiently inelastic demand as a group that a hypothetical profit-maximizing monopoly supplier of the set would impose at least a "small but significant and nontransitory increase in price' (henceforth abbreviated to SSNIP). ${ }^{6}$ A SSNIP is typically, but not rigidly, taken to be a 5 percent increase in price. Conceptually, this analysis begins separately with each of the products of the merging firms and asks whether a hypothetical monopolist over this product would profitably raise its price by 5 percent or more. This question is addressed only in terms of the reaction of demand to the hypothesized price increase, with no attention paid to possible efficiencies created by the merger or to reactions by potential entrants. Such possibly important effects are fully considered in other steps of the guidelines' analysis, while this step of delineating relevant markets focuses exclusively on demand-side effects.

If the hypothetical monopolist would profitably raise its price by 5 percent or more, then this starting-point product alone constitutes a relevant product market. If not, then the product that is the closest substitute to the first product is considered along with it, and the 5 percent test is applied to the two together. It is likely that this group has less elastic demand than the first product considered alone, since diversion of demand from the first to the second now remains within the set.

This conceptual process proceeds until the smallest group of products is found that has the property that a hypothetical profit-maximizing

6. Guidelines, section 2.1. See Boyer (1979) for a valuable precursor. 
monopolist would impose at least a 5 percent increase in price. This group is taken to be the relevant product market with respect to the starting point, one of the products of one of the merging firms.

An analogous process is carried out (simultaneously, in principle) to delineate the geographic scope of the relevant markets. The guidelines mandate consideration of the relevant markets for each of the products (and locations) of the merging firms. The merger is viewed as horizontal if both of the merging parties are included as participants in any one of these relevant markets, and the merger is not horizontal if there is no such overlap. ${ }^{7}$

It is important to note that this process of delineating relevant markets calibrates the market power that is of concern in a horizontal merger. If the merger created a complete monopoly in an overlap relevant market, the analysis predicts that demand would permit the imposition of at least a small but significant and nontransitory price rise for the products and locations in this relevant market. Of course, a host of pertinent questions remains for subsequent steps of the analysis. Prominent among them are the extent to which the merger would structurally or behaviorally create a monopoly in the relevant market, and whether de novo entry would react to or deter the enlargement or exercise of the market power that is of concern. Before turning to these topics, it is necessary to explain a novel feature of the guidelines' step of identifying the firms to be included as participants in the relevant market.

All firms that currently produce and sell any of the products (at any of the locations) that constitute the relevant market are considered participants in it. In addition, "If a firm has existing productive and distributive facilities that could easily and economically be used to produce and sell the relevant product within one year in response to a [SSNIP], the Department will include that firm in the market." ${ }^{, 8}$ Even though such a firm, termed a production substituter, is not currently supplying products in the relevant market, it is nevertheless considered a partic-

7. As a matter of policy, if rigid adherence to the 5 percent figure masks a competitive interaction between merging firms, then a somewhat larger price rise will be employed for the process of market delineation in order to investigate the horizontal nature of the merger. See Rill (1990a). Corresponding adjustments in other steps of the guidelines' analytic process may be appropriate.

8. Guidelines, section 2.21 . 
ipant in it. I shall return to a discussion of this feature of the guidelines in the subsequent part of this paper that focuses on entry.

Once the analytic process has delineated relevant markets, identified the participants in them, and found one or more overlap markets, the next step specified by the guidelines is to calculate and interpret market shares and concentration in the overlap relevant markets. When data permit, shares are determined on the basis of capacity where relatively homogeneous products are involved, and on the basis of sales where the relevant products are relatively differentiated. For production substituters, and other participants with capacity that is utilized elsewhere, the determination of shares is based on only sales likely to be made or capacity likely to be used in the relevant market in response to a SSNIP.

Concentration is measured by means of the Herfindahl-Hirschman Index (HHI), calculated by summing the squares of the market shares (in percentage terms) of all the market participants. ${ }^{9}$ The postmerger HHI is calculated by assigning to the merged firm the sum of the premerger shares of the merging parties, and assigning to the other participants their premerger shares. ${ }^{10}$ The difference between the postmerger and premerger values of the HHI, termed the change in concentration (or the delta), is algebraically given by twice the product of the shares of the two merging firms.

According to the general standards of the guidelines, a horizontal merger will almost never be challenged if the postmerger HHI lies in the "unconcentrated" range below 1,000.11 In the "moderately con-

9. This is a well-known index with many desirable arithmetic properties. It increases if share is transferred from a smaller to a larger firm. For $n$ equal-sized firms its value is $1 / n$, so that $1 / \mathrm{HHI}$ can be interpreted as the "numbers equivalent." If shares are given by fractions, the HHI is 1.0 for monopoly, and it approaches 0 for a large number of firms each having a small share. When shares are measured in percentages, as they are in the 1982 and 1984 guidelines, the HHI runs from 0 to 10,000 .

10. While these assignments may be predictive when shares are calculated according to capacity, they are unlikely to be accurately predictive when shares are based on sales. For example, a merger that creates market power is likely to lead to a decrease in the total share of sales held by the merging firms. See Ordover and Willig (1983); and Farrell and Shapiro (1990a) on this point. Nevertheless, the postmerger HHI can be viewed as an indicator with analytic value apart from its ability to predict concentration after the merger's effects eventuate. See Werden (1990).

11. Guidelines, section 3.11. Here it is pointed out that despite the general standards, "market share and concentration data provide only the starting point for analyzing the 
centrated" range, between 1,000 and 1,800 , there is a virtual safe harbor for mergers that change the HHI by less than 100 , and otherwise, the enforcement decision will weigh a host of other factors along with the level of and change in concentration. In the "highly concentrated" range, where the postmerger $\mathrm{HHI}$ is above 1,800 , the safe harbor applies only to mergers with a delta of less than 50 , and otherwise, "Additional concentration resulting from mergers is a matter of significant competitive concern.", 12

It is key to note that these general standards embody the idea that a horizontal merger of a given size, as measured by the shares of the parties or by the HHI delta, is of greater concern the greater the market concentration. For example, a merger between two firms each with an 8 percent market share (and hence a delta of 128) would lie in the safe harbor if the market were unconcentrated, would trigger an assessment of other factors if the market were moderately concentrated, and would raise "significant competitive concern"' if the market were highly concentrated. In addition, for a given level of market concentration above the unconcentrated range, a horizontal merger is of greater concern the greater the change in concentration it is measured to produce.

\section{Heuristic Theoretical Representation}

Fundamental rationales for the steps of the guidelines' process that have been discussed above can be illustrated by means of a heuristic representation based on IO theory. I term this treatment heuristic because it is deliberately oversimplified and underspecified in order to focus on the connections among market delineation, concentration, and the welfare impact of a merger. This treatment assumes that there are no efficiencies directly or indirectly created by the merger, no dynamic effects, and that there is no possibility of entry into the market. ${ }^{13}$

To the first order in static partial equilibrium, where $d W$ is change

competitive impact of a merger. Before determining whether to challenge a merger, the Department will consider all other relevant factors that pertain to its competitive impact."

12. Guidelines, section 3.11 .

13. See note 19 for additional assumptions that render this model merely heuristic. For somewhat analogous treatments, see Jacquemin and Slade (1989); and Ordover, Sykes, and Willig (1982). 
in consumer plus producer surplus, $d Q$ is change in market output, $P$ is market price, and $c$ is the marginal cost of the market product,

$$
d W=d Q(P-c) .
$$

Taking $\epsilon$ to be the constant elasticity of demand for the market output, $\epsilon=-(d Q / d P)(P / Q)$, and $R$ to be the value $(P Q)$ of market output, (1) can be rewritten as

$$
-d W / R=(d P / P) \in(P-c) / P .
$$

This shows that the welfare impact of a price rise resulting from a merger depends on the elasticity of market demand and on the Lerner index, $(P-c) / P$, applicable to the market experiencing the price rise.

Specification of an oligopoly model is necessary to see how concentration can be related to the welfare impact and to provide a context for the representation of market delineation. Many simple theories of oligopoly have had their equilibria characterized in the following convenient fashion: ${ }^{14}$

$$
(P-c) / P=H \beta / \epsilon,
$$

where $H$ is the HHI and $\beta$ is a parameter that represents the mode of conduct among the firms in the market. ${ }^{15}$ For example, price-taking behavior corresponds to $\beta=0$, Cournot behavior is represented by $\beta=1$, and pure cartel behavior corresponds to $\beta=1 / \mathrm{H}$.

Market delineation can now be represented as the choice of a universe over which to measure concentration such that the monopoly price, satisfying $(P-c) / P=1 / \epsilon$, is 5 percent greater than the current price, satisfying $\left(P^{0}-c\right) / P^{0}=H^{0} \beta^{0} / \epsilon$. This calibration yields the following expression for the elasticity of demand of the products in the relevant market: ${ }^{16}$

14. For example, see Cowling and Waterson (1976); Dansby and Willig (1979); and Bresnahan (1989); as well as Jacquemin and Slade (1989) and Ordover, Sykes, and Willig (1982).

15. Equation (3) is typically built up from the relationship between a firm's price-cost margin and its market share, $s_{i}$ :

$$
\left(P_{i}-c_{i}\right) / P_{i}=s_{i} \beta_{i} / \epsilon .
$$

16. While $\epsilon$ is assumed to be constant with respect to price, it is not invariant to the scope and composition of the relevant market that is delineated here. 


$$
\epsilon=\left(1.05-H^{0} \beta^{0}\right) / 0.05 .
$$

Applying (3) to the market both premerger and postmerger yields these expressions for the percentage change in price caused by the merger:

$$
d P / P=d(H \beta / \epsilon-H \beta)
$$

and substituting (5) and (3) into (2), applying the mean value theorem, and employing (4) yields as the conclusion:

$$
\begin{aligned}
-\triangle W / R^{*}=0.05\left(H^{*} \beta^{*}\right)\left(H^{\prime} \beta^{\prime}-H^{0} \beta^{0}\right) & \\
& /\left(1.05-H^{0} \beta^{0}-.05 H^{*} \beta^{*}\right),
\end{aligned}
$$

where $H^{*} \beta^{*}$ lies between $H^{0} \beta^{0}$ and $H^{\prime} \beta^{\prime}$, and $R^{*}$ lies between $R^{0}$ and $R^{\prime}$.

This result provides a validation of the guidelines' approach to merger analysis. First, note that while equation (2) required knowledge of the market elasticity of demand in order to assess the welfare impact of the merger, this factor does not appear in equation (6) due to the market delineation step that served to calibrate the market power at stake. Instead, the only factors in (6) relate to modes of firm conduct and to concentration, where the universe over which the concentration is measured is set by the market delineation that accounted for the influence of demand. ${ }^{17}$ Second, if the values of $\beta$ were set to a standardized

17. The remarks in note 10 apply to $\mathbf{H}^{\prime}$. Note too that in some contexts, it may be important to recognize that the process of market delineation did not yield a set of products and locations over which a hypothetical monopolist would profitably raise price by only 5 percent. For example, starting with one of the products of one of the merging firms, it might be the case that the hypothetical monopolist would profitably raise the price of that product by a greater percentage, $t$, and that the other merging firm also produces that product. Then the relevant market could not include less than that product. In such cases, the following modification of equation (6) applies, where the value $t$ replaces the 5 percent figure:

$$
-\Delta W / R^{*}=t\left(H^{*} \beta^{*}\right)\left(H^{\prime} \beta^{\prime}-H^{0} \beta^{0}\right) /\left(1+t-H^{0} \beta^{0}-t H^{*} \beta^{*}\right) .
$$

It is straightforward to see that this expression is increasing in $t$. Thus for given values of concentration and for given modes of firm conduct, the larger the percent by which a hypothetical monopolist would profitably raise price over the relevant market, the larger the welfare loss caused by the merger. This is consistent with the statement in section 3.412 of the 1984 guidelines that "the larger the 'gap' at the edge of the product and geographic markets, the more likely the Department is to challenge the merger." 
positive constant level, the influence on welfare impact of the measures of concentration would qualitatively correspond to the ways that concentration enters into the guidelines. Welfare impact is more pronounced the larger the delta, and the impact of a given sized delta is more pronounced the larger the level of concentration. For sufficiently low levels of concentration, the welfare impact of a merger is low even if the delta is big enough to raise concerns at higher levels of concentration. Obversely, at sufficiently high levels of concentration, even relatively small levels of delta can yield sizable welfare impacts.

Equation (6) also shows the importance of the mode of behavior of the firms in the market, and the significance of a change in that mode resulting from a merger. ${ }^{18}$ For constant $\beta$, the greater its value, signifying a less competitive mode of conduct, the greater the welfare impact of a given merger. And the welfare impact of a merger would be greater than that indicated by concentration alone in equation (6) if the merger led to a greater value of $\beta$, and hence to a less competitive mode of conduct. ${ }^{19}$

18. Dansby and Willig (1979) and Ordover, Sykes, and Willig (1982) find that such considerations may well be quantitatively more significant than changes in concentration apart from impacts on the mode of firm conduct. See Stigler (1964) for a model of oligopoly in which the likelihood of collusion is related to the HHI.

19. It is significant to note that all of the above qualitative conclusions would hold if the objective were taken to be consumer surplus instead of the sum of consumer and producer surplus. In this case, equation (6) would apply without the $H^{*} \beta^{*}$ term in the numerator. At this juncture, take note of some of the particular oversimplifications and underspecifications that lead me to term as "heuristic" the model that has just been exercised. First, the formal treatment of welfare presupposes that output is homogeneous, while that surely is not generally the case, especially when the model attempts to represent the process of market delineation. Second, taken literally, the model assumes that all firms have the same levels of constant marginal cost, thus leaving unexplained why different firms might possess different market shares. If firms are thought to have diverse levels of marginal costs, then the welfare measure omits effects arising from transfers of output among firms. Third, the oligopoly representation leaves exogenous the determination of the mode of firms' behavior, while one of the important facets of merger analysis may be the attempt to predict impacts on this very important influence on industry performance. Fourth, the model does not consider the information that may be derived from the fact that the merger is desired by at least one and perhaps both of the parties. And finally, as already noted, the model deliberately abstracts away from complications arising from possibilities of dynamic impacts, entry, and merger efficiencies. 


\section{Assessing Efficiencies}

Efficiencies that might be caused by a horizontal merger enter into the guidelines' analytic process in two ways. First, directly, the department will consider "clear and convincing evidence"' that a merger " may be reasonably necessary to achieve significant net efficiencies." 20 While this precept sounds desirable, serious issues arise in determining what standards should be applied to the ideas of "reasonably necessary" and "significant net efficiencies." Although I believe that economic analysis can contribute much to resolving such issues, they are well outside the scope of this paper. ${ }^{21}$

Second, efficiencies enter intrinsically, though indirectly, into the guidelines' analytic process. "Because the antitrust laws and, thus, the standards of the Guidelines, are designed to proscribe only mergers that present a significant danger to competition, . . . in the majority of cases, the Guidelines will allow firms to achieve available efficiencies through mergers without interference from the Department., 22

More analytically, the guidelines might be viewed as implicitly incorporating the inference of likely significant efficiencies where there is no finding that the merger would significantly increase market power. The profitability of a voluntarily proposed horizontal merger can only stem from some combination of efficiencies, competitively neutral effects, and increased market power. Where the last of these has been found by an investigation to be unlikely or insubstantial, the posterior expected value of the efficiencies is much raised from its prior expected value, even in the absence of direct evidence on efficiencies. Since efficiencies add to social welfare as well as to profit, while increased market power subtracts from social welfare as it adds to profit, the expected social welfare impact of a profitable merger can be readily swung to positive by a finding that the expected addition to profits does not stem from a significant increase in market power. From this consideration, the guidelines' structure of safe harbors with respect to concentration and entry can be analytically derived.

20. Guidelines, section 3.5 .

21. See Williamson (1983) for a stimulating discussion of some of the issues involved.

22. Guidelines, section 3.5. 


\section{Consideration of Other Factors and Competitive Effects in the 1984 Guidelines}

The rich analytical framework established in the 1984 guidelines leaves considerable room for influences beyond market delineation and concentration, even apart from efficiencies and entry. The likely future competitive significance of a firm in the market is to be evaluated directly, in the event it is not accurately reflected by the firm's current share. Many "other factors" are specifically suggested for consideration, especially when the department's decision about whether to challenge a merger is otherwise close. These factors include the degree of heterogeneity of the relevant product; the degree of difference between the products and locations in the relevant market and the next-best substitutes; similarities and differences in the products and locations of the merging firms; information about specific transactions and characteristics of the buyer market; the ability of small or fringe sellers to increase sales; and indications of conduct of firms in the market. All of these other factors are cited as relevant to the extent that they relate to the ease and profitability of collusion. ${ }^{23}$

Indeed, although there is some general language in the guidelines concerning how a concentrating merger might lessen competition, most of the discussion of anticompetitive effects is cast in terms of whether the merger at issue would raise the likelihood of tacit or explicit collusion among the market's suppliers. Until recently, "tacit collusion" might have been interpreted as any oligopolistic behavior that deviated in its outcome from perfect competition, although some texts surely held to finer distinctions. Today, however, with the research literature squarely committed to the conceptual framework of game theory, tacit collusion is associated with a particular class of equilibria in supergames, while other forms of oligopolistic behavior have their own and distinct representations. ${ }^{24}$ Mergers might, for example, be analyzed in the context of a Cournot or a Bertrand oligopoly, an address or a

23. Guidelines, section 3.4.

24. See Friedman (1977); Porter (1983); Green and Porter (1984); and Abreu, Pearce, and Stacchetti (1986) for highlights in the evolution of the association between tacit collusion and supergame equilibria. 
symmetric model of monopolistic competition, a dominant firm model (which is separately evoked in the guidelines under the "leading firm proviso"), or a "carrot and stick" equilibrium of a repeated game with or without complete information. ${ }^{25}$

\section{Fine-Tuning and Clarifying Competitive Effects}

From this perspective, ignoring the general language of the 1984 guidelines and focusing on collusion as the only competitive effect of concern leads to a confining and confusing framework for merger analysis. When analysts or merger proponents are led by the language of the guidelines to focus their attention on collusion in the specific meaning that the term has taken on today, they are likely to overlook possible other competitive impacts of a merger that might be of equal or greater concern in the applicable circumstances. Moreover, some of the guidelines' "other factors" are not relevant to the analysis of competitive effects apart from collusion, and, obversely, some extant or additional "other factors" acquire new and particular importance in the analysis of particular competitive effects apart from collusion. Thus I believe it is a worthwhile challenge to attempt to glean from IO theory an elaboration of horizontal mergers' competitive effects that might be of concern and to link them to relevant patterns of fact and " other factors.'

It may be useful as a matter of terminology to divide theories of possible anticompetitive effects of mergers into two categories: unilateral effects and coordinated effects. Unilateral effects are changes in the actions of the merging firms that would be profitable for them as a result of the merger if the nonparties did not alter their actions or if the nonparties reacted unilaterally themselves. Coordinated effects are changes in the actions of the merging firms that would be profitable for them as a result of the merger only if the changes are accompanied by alterations in the actions of the nonparties that are motivated in part by fears of reprisals. The leading example of coordinated effects is the elevation of prices charged by the merging firms, along with those charged by the nonparties,

25. See Shapiro (1989) or Tirole (1988) for surveys of theories of oligopoly, and Eaton and Lipsey (1989) for a survey of work on monopolistic competition and other market forms with product differentiation. 
where the merger enables tacit collusion to become stable. Here, the price increases are profitable because deviation by a firm would likely trigger retaliatory price decreases. A unilateral effect would arise, in contrast, when a merger between sellers of close substitutes impels them to raise prices profitably whether or not rivals in fact follow. In essence, unilateral effects are those that arise when all market participants undertake unilateral actions, whereas coordinated effects arise from the anticipation of coordinated actions and reactions. ${ }^{26}$

It is the class of coordinated competitive effects on which most of the explicit language of the 1984 guidelines focuses, and these effects remain as important concerns in merger analysis. The guidelines' treatment of such effects and the associated "other factors"' is largely consistent with current economic thought on the subject. ${ }^{27}$ Since it is the class of unilateral competitive effects that is neglected in the language of the 1984 guidelines, it is here that I next place my attention. Although many variants could usefully be analyzed, two stand out as most fundamental. The next section discusses unilateral effects in the context of Cournot oligopoly models of a homogeneous product industry, and the subsequent section focuses on Bertrand oligopoly models of industries with differentiated products. Then the paper turns to a discussion of the treatment of entry in merger analysis.

\section{Cournot Models of Homogeneous Product Industries}

For a century and a half, much of the economics profession's intuition about the connection between market power and concentration has been shaped by Cournot models of oligopoly in homogeneous product industries ${ }^{28}$ Here, as in equation (3) above, equilibrium margins between prices and marginal costs are a decreasing function of the number of

26. Unilateral effects can be represented in a static model, in the repeated stage-game equilibrium of a supergame, or in a supergame where information problems make it impossible for equilibrium strategies to condition current actions on past ones. Coordinated effects can be represented in Nash equilibria of supergames when equilibrium strategies call for actions to depend on the histories of action profiles.

27. See Scherer (1980) for a classic exposition; and Jacquemin and Slade (1989, section 2) and Tirole (1988) for recent surveys.

28. See Shapiro (1989) and Tirole (1988) for background surveys. 
symmetric firms in the industry and an increasing function of each firm's market share. It is straightforward to show that in a Cournot model with symmetric firms, linear demand, and constant returns to scale, the deadweight loss associated with the industry equilibrium, as a fraction of industry sales, is one-half the HHI squared divided by the elasticity of market demand. This evocative result suggests that in the absence of potential competition and efficiency effects, horizontal mergers raise deadweight loss to an extent that increases with the level of concentration and with the change in concentration.

This conventional wisdom was challenged by the demonstration by Salant, Switzer, and Reynolds that in such a model, horizontal mergers without cost savings are unprofitable so long as they are just a bit short of creating a full monopoly. ${ }^{29}$ The possible implication was thought to be that socially inefficient mergers are unprofitable, so that voluntary mergers short of monopoly would necessarily be socially efficient.

Subsequent research stimulated by this challenge suggests otherwise and points to different important lessons. One is the recognition that applicable models must explicitly analyze mergers in terms of the assets they combine. With this approach, Perry and Porter showed that anticompetitive mergers can be profitable, because the rising marginal cost curves resulting from fixed-asset positions dampen postmerger expansion by the nonparties (that is, by the firms not involved in the merger). It is this expansion by the nonparties having constant marginal costs that renders mergers unprofitable in the Salant, Switzer, and Reynolds treatment. ${ }^{30}$

Most recently, and most elegantly, Farrell and Shapiro showed that in general, absent potential competition, synergies, and learning, assetbased mergers elevate prices in a Cournot setting. ${ }^{31}$ They emphasized that such mergers may nonetheless raise welfare inasmuch as they might lead to reallocation of industry output from high- to low-marginal-cost producers. They asserted that the greater the HHI among nonparties, the more opportunity there is for this effect to occur, since the nonparties with relatively large shares have relatively low marginal costs. ${ }^{32}$ How-

29. Salant, Switzer, and Reynolds (1983).

30. Perry and Porter (1985); and Salant, Switzer, and Reynolds (1983).

31. Farrell and Shapiro (1990a, 1990b).

32. See Werden (1990) for a contrary interpretation. 
ever, examples indicate that no observable condition has yet been identified that reveals whether the bigger nonparties are likely to be the ones to accomplish the greater postmerger output expansion; that is, whether output reallocation is likely to be a beneficial side-effect of an otherwise inefficient merger.

I now proceed to introduce a somewhat novel framework that proves powerful for the analysis of the effects of a horizontal merger in a Cournot context. The framework constructs the aggregate best-response function of the nonparties. This is the total output the nonparties would offer, $X$, as a function $N(Y)$ of the total output of the parties, $Y$. Similarly, the aggregate best-response function of the parties, before the merger, is $B(X)$. The best-response function of the merged firm is denoted $A(X) .^{33}$ The premerger Cournot equilibrium is characterized by $X, Y$ such that $B(X)=Y$ and $N(Y)=X$. The postmerger equilibrium is characterized by $X^{\prime}$ and $Y^{\prime}$ such that $A\left(X^{\prime}\right)=Y^{\prime}$ and $N\left(Y^{\prime}\right)=X^{\prime}$. These characterizations are well defined since the second-order conditions and the standard stability conditions imply that the best-response functions are all decreasing. ${ }^{34}$

It generally holds, in the absence of cost savings from the merger, that $B(X)>A(X)$; that is, the merger impels the parties to suppress output, for any given output of the nonparties. ${ }^{35}$ If it were the case that

33. The best response functions are built up in the following fashion: Let firms 1 and 2 be the parties to the merger, firms $3, \ldots, n=m+2$ be the $m$ nonparties, $q_{i}$ be the output of firm $i, C_{i}\left(q_{i}\right)$ be the cost function of firm $i, X=q_{3}+\ldots+q_{n}, Y=q_{1}+q_{2}$, and $P(X+Y)$ be the industry inverse demand function. The best response of firm $i$ maximizes $q_{i} P(X+Y)-C_{i}\left(q_{i}\right)$ with respect to $q_{i}$, holding fixed other firms' output levels. The corresponding first-order condition is $q_{i} P^{\prime}\left(\Sigma q_{j}\right)+P\left(\Sigma q_{j}\right)-C^{\prime}{ }_{i}\left(q_{i}\right)=0$. Taking $q_{1}+q_{2}=Y$ as parametric, there are $m$ such equations for the nonparties, permitting their solution for $q_{3}$, $\ldots, q_{n}$ as functions of $Y$. The sum of these $m$ functions yields $X=N(Y)$. Similarly, there are two such equations for the parties, taking $q_{3}+\ldots+q_{n}=X$ as parametric, permitting their solutions for $q_{1}$ and $q_{2}$ as functions of $X$. The sum of these two functions yields $Y=B(X)$.

After the merger, $N(Y)$ is still applicable, but the situation for the parties is different. Now the merged firm chooses $q_{1}$ and $q_{2}$ to maximize $\left(q_{1}+q_{2}\right) P(X+Y)-C_{1}\left(q_{1}\right)-C_{2}\left(q_{2}\right)$, taking $X$ as parametric, where $q_{1}$ and $q_{2}$ are the amounts to be produced with the parties' premerger technologies, on the assumption of no efficiencies from the merger. The choices of $q_{1}$ and $q_{2}$, as functions of $X$, are added to yield $Y=A(X)$.

34. See Dixit (1982) for an elegant and detailed development of the relationships among second-order conditions, stability conditions, and the slopes of best-response functions. See Shapiro (1989) for a survey treatment.

35. This can be shown by an adaptation of the proof in Farrell and Shapiro (1990a, 1990b) that, without synergies and learning, mergers in Cournot settings raise price. 
Figure 1. Merger Suppresses Total Output

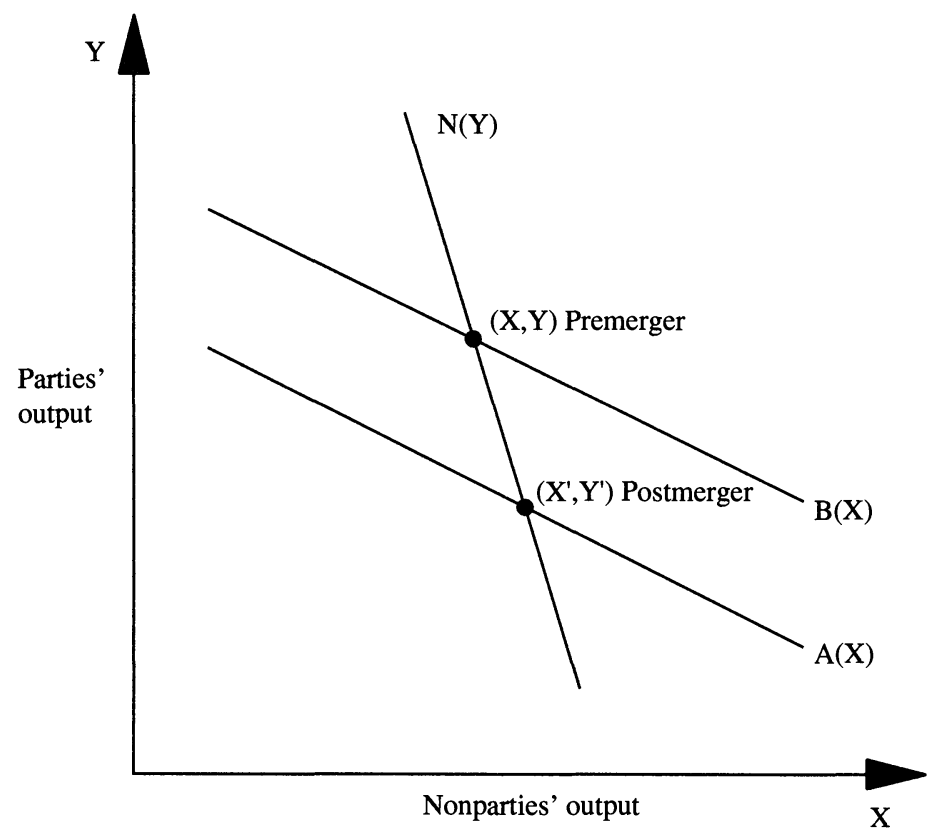

$d N(Y) / d Y=-1$, the nonparties would react to this suppression of output with an equal-sized total expansion of output, thereby leaving the market price unchanged by the merger, and rendering the merger unprofitable. Outside of special cases, however, $d N(Y) / d Y>-1$, and as depicted in figure 1, the postmerger equilibrium as compared to the premerger equilibrium has smaller production by the parties, greater total production by the nonparties, and smaller total output. In the model of costs and capacity utilized by Perry and Porter; Farrell and Shapiro; and Werden, it can be seen that the larger the capacities of the parties, the greater the difference between $A(X)$ and $B(X)$, and hence the larger the rise in market price caused by the merger. ${ }^{36}$

More novel is the result that less concentration among the nonparties corresponds to $d N(Y) / d Y$ being closer to -1 in value. In particular, with $m$ symmetric nonparties having marginal costs that are nonde-

36. In this model, market demand is linear, and a firm's cost of producing $q$ is $c q+$ $q^{2} / k$, where $k$ is its capital stock, or its capacity level. 
creasing convex functions of output, raising $m$ while adjusting the level of their marginal cost curves to keep the premerger equilibrium unchanged has the effect of driving $d N(Y) / d Y$ monotonically toward $-1 .{ }^{37}$ Thus for a given shift due to the merger in the parties' best-response curve, the impact on industry output will be less, the more diffusely spread the total output of the nonparties. With the nonparties replacing the output suppressed by the parties, the merger cannot be profitable in the absence of efficiencies, and if it were profitable, it would not harm consumers. Obversely, the more highly concentrated the nonparties, the less likely they are to make up for the output reduction of the parties. ${ }^{38}$

Another significant finding in this framework pertains to the relationship between the shape of a firm's marginal cost function and the slope of its best-response function. Generally, the greater the slope of its marginal cost curve, holding fixed the relevant level of marginal cost, the greater the slope of its best-response function. Thus the flatter the marginal cost curves of the nonparties, the more elastic their output response to the merger will be, and the less the merger will raise price and profitability increase market power for the parties. ${ }^{39}$

37. Continuing the notation of note 33 , let $q_{i}=q$ and $C_{i}\left(q_{i}\right)=c q_{i}+f\left(q_{i}\right)$ for $i=3$, $\ldots, m+2=n$, where $f^{\prime \prime}(\cdot) \geq 0$ and $f^{\prime \prime \prime}(\cdot) \geq 0$. The first-order condition for each nonparty is $q P^{\prime}(X+Y)+P(X+Y)-c-f^{\prime}(q)=0$, where $X=m q$. Adding these yields this characterization of $X=N(Y): X P^{\prime}(X+Y)+m P(X+Y)-m c-m f^{\prime}(X / m)=0$. We investigate the impact of $m$ on $d N(Y) / d Y$, while varying $c$ with $m$ in order to keep $X$ constant. In this fashion we can uncover the effect of concentration among the nonparties, without altering their total share and the share of the parties as well. The path $c(m)$ along which $X$ is constant has slope $d c / d m=-\left(\partial X / \partial m^{2}\right) /(\partial X / \partial c)=\left[\left(P-f^{\prime}-c\right) / m\right]+f^{\prime \prime} X / m^{2}>0$. Further differentiation of the characterization of $N(Y)$ yields $d X / d Y=-\left[m P^{\prime}(X+Y)+X P^{\prime \prime}(X+Y)\right] /$ $\left[m P^{\prime}(X+Y)+X P^{\prime \prime}(X+Y)+P^{\prime}(X+Y)-f^{\prime \prime}(X / m)\right]$.

Clearly, along the $c(m)$ path that leaves $X$ constant, $d X / d Y$ approaches -1 as $m$ grows large. Moreover, differentiation of $d X / d Y$ with respect to $m$, along the $c(m)$ path, shows that this derivative is assured to be negative if $P^{\prime}+X P^{\prime \prime} / m \leq 0$. It suffices for this that inverse demand be concave or that the nonparties' residual marginal revenue be decreasing in their output with $m \geq 2$.

In the model specified in note 36 , if the capital of each nonparty is inversely proportional to $m$, then as $m$ rises, $D X / D Y$ declines monotonically to a limit greater than -1 .

38. Thus, even where nonparty concentration indicates that output rearrangement among them might bring efficiencies, that concentration can signify that a merger is, on net, more likely to diminish social welfare. Werden (1990) reaches the same conclusion.

39. Let $C_{i}\left(q_{i}\right)=c q_{i}+\alpha f\left(q_{i}\right)$, where $f^{\prime}(\cdot)>0$ and $f^{\prime \prime}(\cdot)>0$. The first-order condition characterizing the best response function of firm $i$ is $q_{i} P^{\prime}\left(q_{i}+Z\right)+P\left(q_{i}+Z\right)-c-\alpha f^{\prime}\left(q_{i}\right)=0$, where $Z$ is the total output of all other firms in the market. Here we investigate the impact 
The following lessons for merger analysis are suggested by these results. In a Cournot homogeneous-product setting, a merger between firms with significant market shares raises the concern that they will find it profitable to suppress their output. This incentive arises because their combined postmerger base of capacity and output makes the consequent rise in price applied to the bigger base outweigh the lost markup on the suppressed sales. There may be offsetting efficiency gains from expansion by nonparties with large shares, but these are difficult to predict. If the nonparties have unconcentrated shares of sufficient total magnitude, or if nonparties having significant total share can individually expand with little cost penalty, then consumers are likely to be protected by the incentives of the nonparties to expand. In such an instance, the parties are unlikely to find their merger profitable unless it creates synergies or other forms of genuine cost savings, and such efficiencies might be inferred from the voluntary character of the combination. In these circumstances, the merger is likely to be socially beneficial.

Little doubt should remain that Cournot models can provide a productive setting for derivation of rich results concerning unilateral competitive effects of horizontal mergers. A remaining question, however, is the applicability of these models to the analysis of real mergers. ${ }^{40}$ At their foundational level, these models are based on a particular view of business behavior - that firms unilaterally decide on their levels of output to be sold and that the level of price is that which clears the market of the total output produced. ${ }^{41}$ This view of business behavior

of varying $\alpha$, which parameterizes the slope of the firm's marginal cost curve, along the path $c(\alpha)$ that leaves $c+\alpha f^{\prime}\left(q_{i}\right)$ unchanged, and hence $q_{i}(Z)$ unchanged. The slope of the best-response function is $d q / d Z=-\left(P^{\prime}+q_{i} P^{\prime \prime}\right) /\left[2 P^{\prime}+q_{i} P^{\prime \prime}-\alpha f^{\prime \prime}\left(q_{i}\right)\right]$. The derivative of this slope is positive with respect to $\alpha$, along $c(\alpha)$, provided that $q_{i} P^{\prime \prime}+P^{\prime}<0$, which follows from a declining market marginal revenue curve and $q^{\mathrm{i}} \leqslant Z$.

40. See the debate in this volume among Franklin Fisher and his discussants and commentators.

41. An important advance by Kreps and Scheinkman showed that the Cournot model could apply to a different scenario where symmetric firms first unilaterally commit to their levels of capacity, and, subsequently, compete with each other by setting prices. However, recent work by Deneckere and Kovenock (1989) shows that simultaneous capacity investment decisions followed by a second-stage pricing game do not necessarily lead to Cournot outcomes when the firms have significantly different levels of variable cost. In addition, Herk (1990) explores the variety of results that can be obtained from such games as the 
may very well be a sufficiently apt description of unilateral conduct in markets for commodity products where production capacity and production runs play important roles. However, there is little reason to believe that Cournot models are sufficiently descriptive when firms have direct control over the pricing of their proprietary differentiated products and when production levels can be readily adjusted in response to demand. For such circumstances, the Bertrand models discussed in the next section are far more appropriate.

\section{Differentiated Product Bertrand Models}

Differentiated product Bertrand models describe firms' unilateral incentives to set prices for their proprietary products. Here it is clear that in the absence of potential competition and efficiencies, horizontal mergers between sellers of substitutes create incentives for price elevation by the parties, and that rival nonparties have incentives to raise their prices in response. This was shown in a rather general setting by Davidson and Deneckere. ${ }^{42}$

The articulation is that, premerger, firms set price to balance the added revenue on inframarginal sales against the lost markup on diverted sales. Postmerger, this balance is upset to the extent that a share of the diverted sales would go to a product of the merger partner, so that the lost markup is offset by added net revenue from added sales of that product. Thus, to the first order, the incentive to raise the price of good 1 following a merger with the seller of good 2 is greater the larger the product of the markup on 2 and the derivative of the demand for 2 with respect to the price of 1 . This cross-price derivative is meaningfully scaled in relation to the absolute value of the (own-price) derivative of the demand for 1 with respect to the price of 1 , to indicate the share of the marginal sales of 1 that would divert to 2 . Of course, the obverse holds for the incentive to raise the price of good 2 following the merger. ${ }^{43}$

demand-rationing mechanism is varied. Two-stage capacity games might be further modified to incorporate the anticipated possibility of subsequent mergers.

42. Davidson and Deneckere (1985).

43. These effects can most readily be seen in the context of a linear model of two substitute products. Let the demand for goods 1 and 2 be $Q_{1}=a_{1}-b_{1} P_{1}+g P_{2}$ and 
Consequently, in principle, a direct way to ascertain whether a merger between sellers of differentiated products raises concern is to estimate the ratios of cross-price and own-price derivatives of demand for the relevant products, in conjunction with the pertinent price-cost margins. The larger in absolute value these ratios, the more the premerger competitive restraints on the pricing of the parties' products arise from the products of the merger partner, and so the more likely (absent other important considerations) the merger is to diminish competition and drive up prices.

There may well be circumstances where data and time permit econometric estimation of the requisite demand system in order to inform enforcement decisionmaking about mergers. There may also be circumstances where business records or other sources of information permit sound inferences to be drawn in a more qualitative fashion about the key concepts of demand.

On the face of it, this perspective appears to remove consideration of market shares from merger analysis since there are no obvious sys-

$Q_{2}=a_{2}-b_{2} P_{2}+g P_{1}$. Facing constant marginal costs of $c_{1}$ and $c_{2}$, independent sellers of the two goods would maximize their separate profits in the Bertrand fashion by charging prices that satisfy these first-order conditions:

$$
\begin{aligned}
2 b_{1} P_{1 o}-g P_{2 o} & =a_{1}+b_{1} c_{1} \\
-g P_{1 o}+2 b_{2} P_{2 o} & =a_{2}+b_{2} c_{2} .
\end{aligned}
$$

After a merger of these sellers, they would set $P_{1}{ }^{\prime}$ and $P_{2}{ }^{\prime}$ to maximize the total profits derived from these products. These prices would satisfy:

$$
\begin{aligned}
2 b_{1} P_{1}{ }^{\prime}-2 g P_{2}{ }^{\prime} & =a_{1}+b_{1} c_{1}-g c_{2} \\
-2 g P_{1}{ }^{\prime}+2 b_{2} P_{2}^{\prime} & =a_{2}+b_{2} c_{2}-g c_{1} .
\end{aligned}
$$

While these two systems could be easily solved and their solutions compared, it is more revealing to rearrange them to see that

$$
\begin{aligned}
& \left(P_{1}{ }^{\prime}-P_{1 o}\right)=g\left(P_{2 o}-c_{2}\right) / 2 b_{1}+g\left(P_{2}{ }^{\prime}-P_{2 o}\right) / b_{1} \\
& \left(P_{2}{ }^{\prime}-P_{2 o}\right)=g\left(P_{1 o}-c_{1}\right) / 2 b_{2}+g\left(P_{1}{ }^{\prime}-P_{1 o}\right) / b_{2} .
\end{aligned}
$$

The first of these says that the merger will elevate the price of good 1 according to two effects. One focuses on the initial price-cost margin of good 2, multiplied by the absolute value of the ratio of the cross-price and own-price derivatives of demand for goods 2 and 1. The second effect adds further price elevation to good 1, depending on the elevation in the price of good 2 and the same ratio of demand derivatives. Analogous effects apply to the pricing of good 2 .

It should be noted that in a larger demand system, encompassing additional substitute products sold by non-parties, there would be further impetus to elevation of the prices of 1 and 2 arising from unilateral elevations of the nonparties' prices. 
tematic relationships among market shares and cross-price derivatives of demand. However, there are rigorously characterized scenarios in which market shares can be accurate indicators of the competitive effect of a merger between producers of differentiated products. In those circumstances, the bigger the market share of 2 , the more attractive a product it is, and so the more appealing it is as an alternative to those who buy 1 . Thus the bigger the share of 2 , the more of the marginal buyers of 1 who would divert to 2 in reaction to a rise in the price of 1. Further, the more attractive 2 is, the lower (in absolute value) its own price elasticity of demand is likely to be, and hence the greater its price-cost margin is likely to be. On both scores, then, the bigger 2 's share, the more the merger will drive up the price of 1 , and obversely. Moreover, the bigger the shares of other goods in the market, the smaller (in absolute value) their own price elasticities of demand, and thus the greater their price-cost margins. Hence, the greater the welfare loss will be from decreases in their outputs caused by the increases in their prices that are unilaterally profitable responses to the price increases on the merging parties' products.

There are several formal ways to model scenarios of this kind. The value in doing so for present purposes is to carefully expose the substantive content of the underlying assumptions. We shall see that the assumptions are unlikely to be valid in many areas of application where specific information can be developed about product characteristics and about consumer preferences for them. For such applications, merger analysis that focuses exclusively on market shares is likely to go awry. Nonetheless, the models suggest that merger analysis in terms of concentration can be valid in the absence of specific information concerning the detailed structure of products' demand and that market concentration can be a valid benchmark for adjustment in response to incomplete information about demand.

Formally, let $U_{i}$ be the random utility derived by a particular representative consumer from one unit of good $i$. The consumer will choose $i$ from the set $S$ if $i$ yields the greatest utility of all options in $S .{ }^{44}$ The structure of these random preferences is said to satisfy Luce's Choice Axiom if the ratio of the probabilities that $i$ and $j$ respectively are chosen

44. See Perloff and Salop (1985) for the first model of oligopoly based on such foundations for demand. 
from the set of alternatives $S$ is invariant to the membership of $S .{ }^{45}$ This implies, but is stronger than, the condition that $U_{i}$ is uncorrelated with $U_{j}$. Luce showed that it is necessary and sufficient that there exist values $V_{i}$ such that the probability that $i$ is chosen from the set $S$ is equal to $V_{i} / \sum V_{j}$. Then, $s_{i}$, the market share of $i$ out of the universe $N$, is $V_{i} / \sum_{N} V_{j}$. Consequently, with a large population, the probability that 2 is second best for a consumer choosing 1 is

$$
\frac{V_{2}}{\sum_{N} V_{j}-V_{1}}=\left(\frac{V_{2}}{\sum_{N} V_{j}}\right)\left(\frac{\sum_{N} V_{j}}{\sum_{N} V_{j}-V_{1}}\right)=\frac{S_{2}}{1-S_{i}} .
$$

Thus for preferences having this strong independence property, the greater the shares of 1 and 2 among the products in the market, the greater the expected number of buyers of 1 who find 2 their favorite alternative to 1 .

A convenient demand system built up from such a random utility foundation is the logit. ${ }^{46}$ Here, the demand for product $i$ at prices $p_{j}$ is given by

$$
\alpha_{i} e^{-P_{i}} / \Sigma \alpha_{j} e^{-P_{j}}
$$

This system has the properties that the own-price derivative of demand for product $i$ is $-s_{i}\left(1-s_{i}\right)$, and the derivative of the demand for $j$ with respect to the price of $i$ is $s_{i} s_{j}$.

Then, this demand system has the very features highlighted above.

Products with relatively large shares have relatively small positive own-price elasticities of demand.

For a product $j$ with a relatively large share there is a relatively large absolute value $\left(s_{j} / 1-s_{i}\right)$ of the ratio of the derivative of its demand with respect to $p_{i}$ to the derivative of the demand for $i$ with respect to $p_{i}$. Consequently, for a market where the structure of demand was well represented by the logit model, or by preferences that satisfy Luce's Choice Axiom, analysis of horizontal mergers would be accurately based on market shares, together with entry and efficiencies and other

45. See Luce (1959).

46. See Anderson and de Palma (1990); and Besanko, Perry, and Spady (1991) for applications of logit demand systems to oligopolies with differentiated products. See McFadden (1973) for the fundamental econometrics of such systems. 
pertinent factors. Relatively high shares of the merging parties and relatively high concentration among the nonparties would signify, other things equal, greater reason for concern that the merger would raise the parties' prices and cause significant welfare losses.

It is crucial to recognize that this conclusion rests sensitively on the substance of the assumptions underlying the demand systems. Consider the assumption that a consumer's random preferences for products 1 and 2 are stochastically independent. If products 1 and 2 are close in their endowments of particular salient characteristics, then for those consumers whose $U_{1}$ is large, $U_{2}$ will be large also, and conversely, so that the random utilities will be positively correlated across consumers. Obversely, if the products are unalike in their salient characteristics, the random utilities will be negatively correlated. Either way, the assumption of stochastic independence would be wrong.

Consider, next, the assumption of Luce's Choice Axiom. Suppose, for example, that product 3 is closer to product 1 than to product 2 in salient characteristics, and that product 4 is closer to product 2 than to product 1 . Then the ratio of the probabilities that 1 and 2 will be chosen will be smaller with respect to the set $\{1,2,3\}$ than to the set $\{1,2$, $4\}$, thereby contradicting Luce's Axiom.

Finally, consider the possibility that instead of the logit model, a nested logit were the better representation of demand. ${ }^{47}$ Then, cross elasticities of demand would depend not only on market shares, as in the logit representation, but also on whether the two products were found to be on the same branch of the tree. Similarly, the relationships between own-price elasticities and market shares would be different for different branches of the tree.

From each of these perspectives, rejection of the strong assumptions on the structure of preferences and demand in a particular market would imply rejection of the foundation for the primary reliance on shares of that market in merger analysis. From each of these perspectives, the reason for the rejection is information that indicates that the products in the market are differentiated by characteristics salient to consumers and that relevant products vary in their similarities to one another in regard to these characteristics. Thus the inferences from market shares

47. See Anderson and de Palma (1990) for developments of oligopoly models in markets with logit and nested logit demand systems. 
in this setting are valid only if the products are neither markedly close nor distant from one another in the space of salient characteristics. Otherwise, the products' shares either understate or overstate the expected competitive effects from a merger between their sellers.

It is significant in some settings to recognize that products in a relevant market may have a clustered or local structure to their demand interactions without the salient characteristics being evident to an outside observer. For such instances, the framework of random preferences presented above may be of direct value. For example, where consumers invite in sellers to make bids, the stochastic correlations of the matchups can be investigated. If independence were found, reliance on market shares would be supported, and positive (negative) correlation between the matchups involving merging parties would indicate that the shares understate (overstate) likely competitive effects.

I believe that this is the first rigorous identification of circumstances in which it is appropriate to rely on market shares in the analysis of mergers in differentiated product markets. This finding provides a basis for the use of shares when the associated assumptions fit, and perhaps when there is no better information available on the structure of demands. The analysis here also points to the strong need to develop information beyond shares in markets with differentiated products, particularly the relative proximity of the products of the merging firms in the space of salient characteristics. And finally, the analysis shows that reliance on shares is the benchmark that logically corresponds to the case of stochastic independence of the appeals that different relevant products have across the population of the market's consumers. Hence, information about positive or negative correlation of these degrees of appeal should be considered as grounds for deviation from the benchmark provided by market shares.

Before leaving this subject, an important caution should be emphasized. The above discussion proceeded on the implicit assumption that the pattern of demand relationships and products' characteristics are not subject to endogenous change. Although this may be an accurate assumption in many contexts, in others firms may be readily and quickly able to reposition their products in response to market incentives. As such, there would be little reason for special concern about the effects of a merger between two firms just because their products happened to be close substitutes at the current point in time. If they were to merge 
and raise their prices, they would be likely to find their rivals repositioning their products in response-in a fashion that would at once protect consumers and render unprofitable a price rise and perhaps an anticompetitive merger itself.

\section{Clarifying Entry Considerations}

What a businessperson would call entry appears in the guidelines in two different forms. As already discussed, a firm is termed a production substituter if it could enter into supply of a relevant product in response to a SSNIP within one year, without the need to commit significant investment in new facilities. A firm is called an entrant instead of a production substituter if its reponse would take longer than a year, or if its new supply of the relevant product would require significant commitment to new investment. The guidelines hold that production substituters should be considered participants in the relevant market; they should be assigned market shares based on an assessment of what their sales of or capacity for producing the relevant products would be in reaction to a SSNIP; and their market shares should be included in calculations of the market's concentration both before and after the merger.

To see why this is an accurate way to analyze unilateral competitive effects, consider the following two-stage oligopoly game. In the first stage, symmetric firms A, B, and C simultanteously choose the capacities of the stamping machines in which they will be irreversibly investing. In the second stage, the firms play a pricing game over the sale of the services of the stamping machines (with the institution of efficient rationing). By the results of Kreps-Scheinkman, the equilibrium of the two-stage game has each firm fully utilizing its capacity, which is equal to the level of quantity that would have been the solution to a one-stage Cournot game. ${ }^{48}$ The demand for the machines' services is derived from the demand for mailboxes and hubcaps, which can only be produced by the addition of elastically supplied inputs to the stamping machines. Firms $\mathrm{A}$ and $\mathrm{B}$ wind up producing mailboxes, and firm $\mathrm{C}$ produces hubcaps.

48. Kreps and Scheinkman (1983). 
An analyst coming upon a merger between $\mathrm{A}$ and $\mathrm{B}$ might ponder how to treat firm $\mathrm{C}$, since he or she would be focusing on the market for mailboxes, delineated in terms of demand. However, the model makes it clear that the merger fundamentally is between two of the three sellers of services of stamping machines. This correct perspective is equivalent to the perspective suggested by the guidelines: define the relevant product market to be mailboxes and consider firm $\mathrm{C}$ a full participant since it is a production substituter from hubcaps to mailboxes.

In this respect, the guidelines' approach defines an insightful analytic path. Here, if one knew that the fundamental competition at stake centered on stamping machine services, one couldn't do better than follow the equivalent procedure suggested by the guidelines. However, if one did not know that to be true, following the guidelines' process would either reveal the equivalent approach, or, on different facts, lead to a different conclusion.

Entrants who must commit to significant new investments are treated differently from production substituters in the guidelines. They are not counted as participants in the market for calculation of concentration either before or after the merger. In order for a firm to be considered a potential entrant under the guidelines, it must be the case that it would be likely to enter in response to a SSNIP that persisted over the course of two years. However, IO theory today rarely considers price a state variable in dynamic settings where investment commitments are under analysis. While contemporaneous prices may influence the anticipated profitability of entry as a result of such factors as incumbents' menu costs, incumbents' reputations in the eyes of buyers, inferences about information that is private to the incumbents, and opportunities for medium- and long-term contracts between buyers and entrants, predictions of postentry prices, which may be unrelated to preentry prices, must also be seen as playing a role. Of course, this role is more important the more significant the sunk costs needed to effect efficient entry.

Rather than focus primarily on price, current IO theory would evaluate entry commitments in response to the competitive effect of concern. This competitive effect could be taken to be a diminution of competition that would cause a SSNIP in the absence of entry. Alternatively, the competitive effect could be the particular one, or several, that emerge 
as concerns from stages of guidelines' analysis that could precede entry analysis.

Evaluating entry commitments as possibly responding to the competitive effect of concern places the focus on the change in the anticipated profitability of entry caused by the structural change inherent in the merger, rather than on the effects of hypothetical price rises. Then, viewed from the perspective of a typical dynamic IO model of unilateral competitive effects, likely, timely, and sufficient entry would deter anticompetitive mergers, not anticompetitive price rises after a merger. Thus, if potential entry met these criteria of effectiveness, voluntary mergers could be inferred to arise from forces distinct from any increase in market power. One possible inference would be that the competitive environment would not in fact be softened by the merger, and an alternative inference would be that any softening of the competitive environment would be offset by efficiency gains created by the merger. Either way, the conclusion would be that the merger was harmless.

The different treatments of production substitutability and entry could then be encapsulated as follows: Production substituters are in the market pre- and postmerger and should be taken into account as part of the competitive environment in which the merger is occurring. Indeed, should it be the case that there are practically unlimited sources of such potential entry within one year, and without the need for commitment to significant irreversible investment, then inclusion in the market of this group of production substituters would necessarily drive concentration measures into the safe-harbor range. ${ }^{49}$ In contrast, entrants who might be induced by the merger to sink significant costs in order to participate in the market may or may not be predicted to bring sufficient new competition to replace the competition otherwise lost as a result of the merger. ${ }^{50}$ Here, the likelihood, timeliness, and sufficiency of the induced entry are the critical elements of the analysis.

49. In such circumstances, this method of analysis would reach the same conclusion about the impact of a horizontal merger as would the theory of contestable markets. See Baumol, Panzar, and Willig (1982).

50. From this point of view, there is nothing wrong in the following seeming paradox: findings of the need for entrants to sink significant costs can mean that potential entry is strong enough to allay concerns about a merger, whereas findings of no need to sink costs by a limited group of firms can mean that the resulting supply-side substitution is not strong 
Figure 2. Merger without Entry

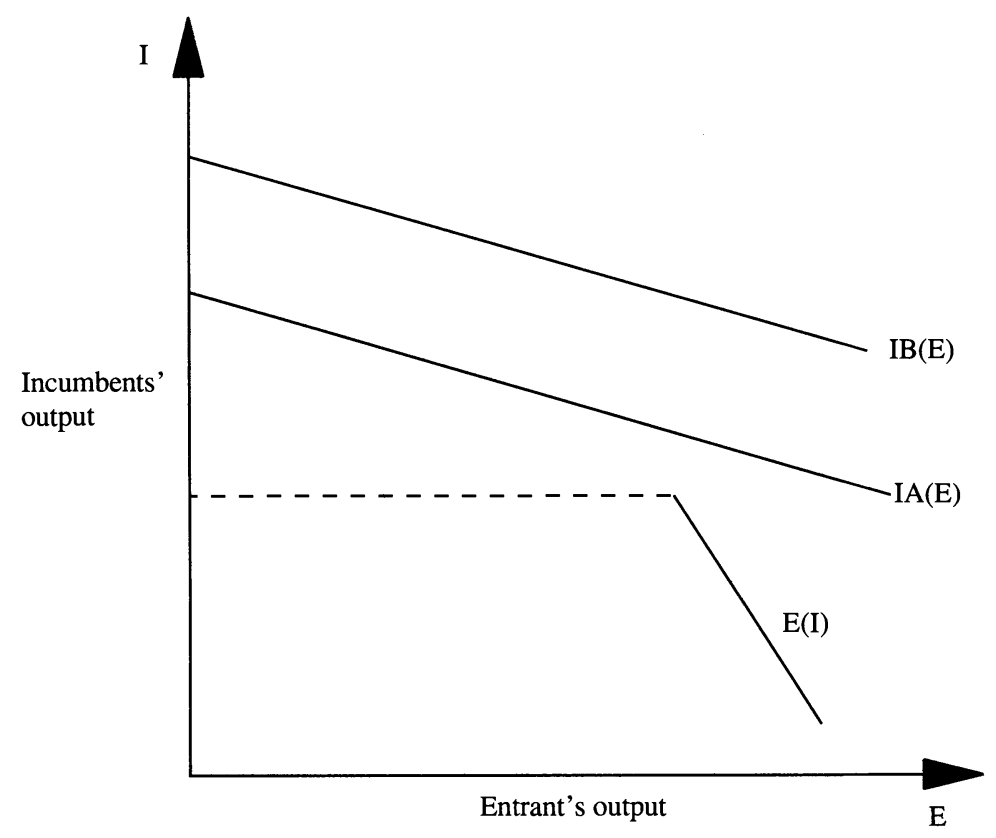

The following example illustrates important facets of the analysis of entry that require significant commitment. Suppose that the interactions among old and new incumbents in the relevant market can be described by a Cournot model. As shown in figures 2 and 3 , if entry were to occur with output $E$, the best responses of the incumbents would total $I B(E)$ before the merger, and the smaller level of output $I A(E)$ after the merger. Entrants' total best response to incumbents' total output of $I$ is given by $E(I)$. Before the merger, market output is $I B(0)$, since the potential entrants are not then participating in the market. If entry were not induced by the merger, postmerger industry output would be $I A(0)$, and price would signficantly rise.

Figure 2 illustrates a case in which entry would not be induced by

enough to alleviate the concerns.

Were the limited group of potential entrants production substituters, their influence on competition would already be reflected in the market price, while if they were instead entrants facing the need to sink costs, their influence on competition would not be present unless induced to commit to the market by the merger. 
Figure 3. Merger Induces Entry

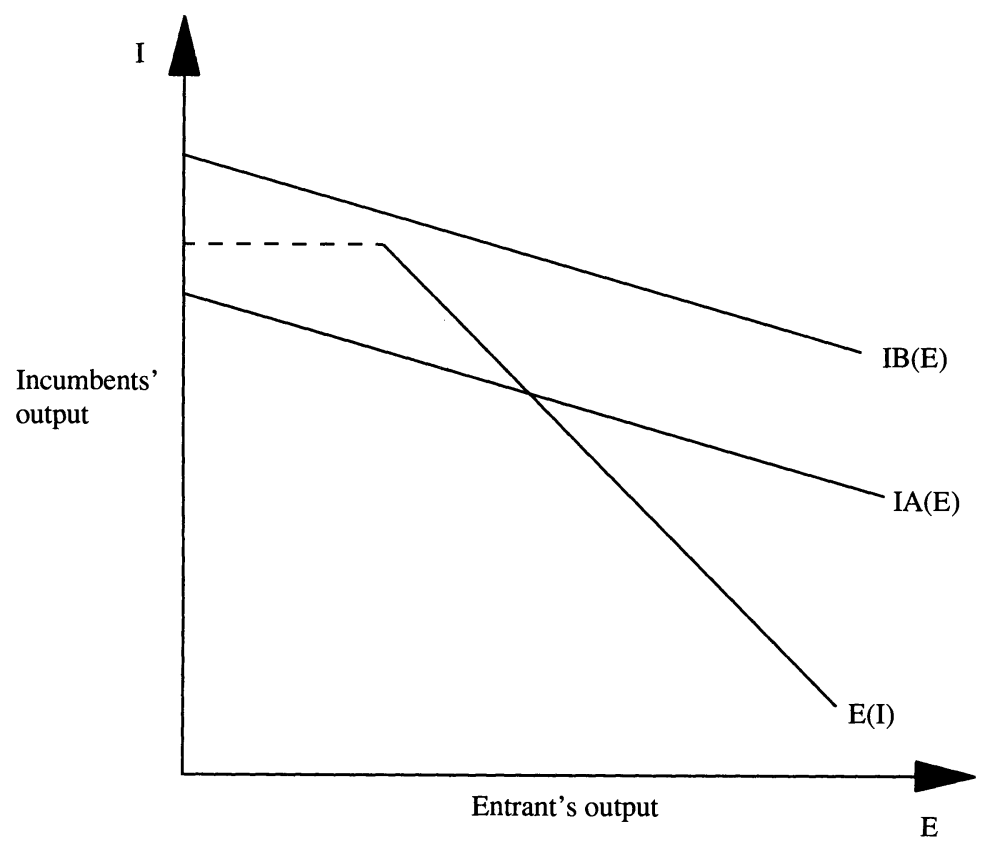

the merger. This can be seen from the lack of an intersection between $I A(E)$ and the positive region of $E(I)$. Here, $E(I)$ cuts discontinuously to 0 where the output of incumbents is too large to leave sufficient room for entrants to sell enough to cover their fixed and sunk costs of setup. ${ }^{51}$ Consequently, the merger would be anticompetitive, and the indicated conclusion would be to challenge it.

In contrast, figure 3 illustrates a case in which merger would induce entry, and the postmerger equilibrium is given by the intersection between $E(I)$ and $I A(E)$. Here, as pictured, total industry output has not fallen from the premerger level of $I B(0)$, although a portion of this output has been shifted from the incumbents to the entrants. Thus the merger is unlikely to be profitable, unless it brings about efficiencies. The conclusion of this analysis would be that the merger would be

51. More carefully phrased, at this level of incumbent output the residual demand curve available to an entrant lies everywhere below the entrant's average total cost curve. See the survey by Gilbert (1989) for more detail on such constructs and for further references on the subject. 
unlikely to raise price and suppress output, as a result of likely entry sufficient to replace the feared diminution of competition. In fact, the analyst would suspect that the merger, in view of its being voluntary, would likely be socially beneficial as a result of efficiencies inferred from the lack of anticompetitive effect.

The difference between figures 2 and 3 lies only in the location of the discontinuous cut to 0 in $E(I)$. In figure 3 , the entrants can cover their total costs at a higher level of incumbents' output, because the fixed and sunk costs needed for entry are smaller. This contrast places the focus on entrants' minimum viable scale (MVS) - the smallest scale of output at which an entrant would expect to cover its complete entry and operating costs at current levels of price. ${ }^{52}$ As the figures illustrate, the smaller the MVS is for entrants, the more likely there is to be an intersection between $I A(E)$ and the positive portion of $E(I)$, signifying that an otherwise anticompetitive merger would trigger entry that might be sufficient to replace the feared loss in competition.

It should be clear that the facets of the analysis of entry requiring significant commitment that have been illustrated in the above setting apply in other settings as well. Consider, for example, a merger between sellers of substitute differentiated products with unilateral competitive effects of concern. Here, absent efficiencies and entry possibilities, the parties will find it profitable to raise their prices as a result of the merger, and the nonparties are likely to raise their prices as well. The issue then becomes whether this softened competitive environment will be sufficiently attractive to induce entry commitments that would have been unprofitable without the merger. The added inducement to entry is that postmerger incumbents' prices will be higher for any given set of offerings by entrants than they would have been without the merger, thereby presenting entrants with more demand for their substitute products. This enriching of the opportunities available to entrants is more likely to swing to positive their anticipated profits the smaller their MVS and the smaller the required amount of sunk cost that entry places at risk.

In general, when entry does require a commitment of significant sunk costs, the smaller the MVS, and the smaller the necessary sunk costs associated with that scale of entry, the more likely entry is to either

52. See Salop (1986) for the original explanation of this concept. 
cure a loss of competition or to give comfort that the merger must not be anticompetitive even in the absence of actual entry. Without attempting a complete list, it is clear that the less important scale economies are, the more flexible production is; and the less important commitment to advertising expenditures is and the more fungible production facilities are, the smaller the MVS and the accompanying sunk costs are likely to be.

These considerations do not obviate analysis of other possible impediments to entry. The longer it would take for entry to be effectively accomplished, regardless of its ultimate profitability, the longer the time would be that the parties to an anticompetitive merger could profit before experiencing the negative impact of the entrants' arrival in the market; the longer consumers would be vulnerable to elevated prices; and the less likely potential entry would deter an anticompetitive merger. For potential entrants to be able to respond to a merger's diminishing of competition, they must have the necessary inputs and technology available to them on terms that make their average costs comparable to prevailing market prices, and they must not face daunting legal impediments.

Thus, in any setting, gauging the power of potential competition to replace competition lost as a result of merger requires a multifaceted assessment of various factors. There can be no doubt of the value of a coherent framework drawn from IO theory to suggest the relevant factors, organize them, and determine their relative importance. Ideally, the consideration of potential competition and competitive effects would be closely linked in a common scenario, so that the analysis could focus on the key question of whether timely entry would be likely to replace the loss of competition that is of concern.

\section{Conclusion}

It is easy to assert that further research would be productive in generating more understanding of the competitive effects of horizontal mergers and which observable factors should play roles in their assessment. Perhaps the least explored, and one of the more important, areas for such research is the possible impact of horizontal mergers on competition for innovation. While there is a copious literature on con- 
nections between concentration and research and development, little of it has taken the asset-based approach that is now understood to be necessary for the meaningful theoretical study of mergers. ${ }^{53}$ Yet it is a commonplace in today's economy that innovation is an important battleground for competition, and it seems evident that market power and efficiencies based on asset holdings play significant roles in shaping its contours and vigor. It would not be surprising to find that merger enforcement policy articulated in a discussion of its impacts on prices and static deadweight loss does in fact work to preserve competition in innovation at the same time. Whether or not this is the case and what additional analytic steps might be warranted from this perspective are questions that press for further research.

It is even easier to assert that more empirical work would be of great benefit to bolster an understanding of the mapping between observables and industry performance and to test theories of how to assess the impacts of mergers. ${ }^{54}$ Nevertheless, even while calling for more pertinent research, I am pleased to assert that a great deal is already known that is of real benefit to the task of assessing the effects of horizontal mergers.

The 1984 guidelines reflect much of that knowledge and are well connected to IO theory. Fine-tuning and clarification can deepen and enrich those connections and strengthen the guidelines as a forensically useful framework for merger analysis.

53. See Ordover and Willig (1985) for a modest start down this path.

54. See Bresnahan (1989) and Schmalensee (1989) for surveys of the empirical literature dealing with industry market power and structure and performance. See Kessides (1986) and Hurdle and others (1989) for excellent recent empirical studies of the causes and effects of potential competition. There are very few empirical studies of the effects of mergers. See Barton and Sherman (1984); Werden, Joskow, and Johnson (1991); and Schumann, Rogers, and Reitzes (1990). 


\section{Comments and Discussion}

Comment by Steven C. Salop: The Department of Justice (DOJ) merger guidelines were released on June 14, 1982, and revised guidelines were issued on June 14, 1984. Two important items on the agenda for the current DOJ administration are revision of the guidelines' treatment of entry and noncollusive, unilateral conduct. Robert Willig has made an exciting and provocative start on this agenda. In this comment, I first will review those aspects of the current guidelines that create the context and then discuss the new approach in some detail. ${ }^{55}$

\section{Entry in the DOJ Merger Guidelines}

The DOJ merger guidelines are formally premised on a fear of collusion (both express cartels and tacit pricing coordination). The guidelines suggest that a merger may facilitate such collusion by reducing the number of independent firms and by raising market concentration. The " 5 percent" test that forms the basic methodology of the guidelines' approach to market share and entry flows as a matter of first principles out of this model of pricing coordination.

In the context of entry, the guidelines ask whether substantial entry will occur within two years if a hypothetical monopolist or cartel engages in a "small non-transitory increase in price" (that is, a SSNIP). If so, then the fear of such "easy" entry would deter collusion or pricing coordination by the established firms after the proposed merger

55. These comments are preliminary because the ideas are still evolving. I would like to thank Robert Willig for helpful conversations and many of the ideas in this comment. 
is consummated. In this case, the merger may be permitted without fearing postmerger price increases.

\section{Shortcomings in the DOJ Approach}

Although it is simple and intuitive, this analysis of ease of entry in the DOJ guidelines is unsatisfying for two reasons.

First, although ease of entry has primacy in the guidelines in the sense that easy entry makes even merger to monopoly permissible, the guidelines do not provide detailed analysis of entry. Compare the guidelines' evaluation of industry concentration. The guidelines measure concentration with the Herfindahl-Hirschman Index (HHI). They then distinguish three separate categories for postmerger HHI levels (under 1,000 ; between 1,000 and 1,800 ; over 1,800 ) and three categories for the change in the HHI (under 50; 50-100; over 100) and categorize each merger accordingly. In contrast, ease of entry, the more important variable, is not quantified and finely graded the way concentration is. ${ }^{56}$ Indeed, the guidelines do not state explicitly whether they are concerned with Stiglerian or Bainian barriers to entry.

Second, the theory of entry underlining the guidelines does not satisfy modern industrial organization theory. The SSNIP-based definition essentially aims to gauge an ex ante supply curve of entry, that is, the relationship between the preentry (but postmerger) price and the subsequent entry of new capacity. This model works fine in perfectly contestable markets, where there are no sunk costs. ${ }^{57}$ The problem is that sunk costs are the norm, especially in markets characterized by product differentiation and customer loyalty to established brands. If there are sunk costs, then there may be no causal relationship between entry and the preentry price.

For example, in the simplest model of Bertrand price competition among duopolists with identical constant marginal costs, the postentry price is driven to marginal cost. In this model, if entry entails even

56. The guidelines do grade ease of entry into two categories. "Supply substitution" is capacity that can enter the market within one year in response to a SSNIP whereas "new entry" is capacity than can enter within two years. Merger analysts also commonly view entry as involving far greater sunk costs than supply substitution, but that distinction is not contained explicitly in the guidelines.

57. Baumol, Panzar, and Willig (1982). 
trivial sunk costs, the entrant would suffer a loss. If this loss is anticipated, no entry will occur. Thus the incumbent can raise price to the monopoly level with impunity, without fear of entry. The preentry price is irrelevant to the entry decision. ${ }^{58}$ In short, even trivial sunk costs destroy market contestability in the presence of postentry price competition.

There are a number of ways in which this "supply curve of entry" approach might be saved. Suppose the entrant might enter secretly, in the sense that customers will enter into long-term contracts with an entrant who offers a price below the preentry price. In this case, the entrant can become established before getting into a price war with the incumbent. ${ }^{59}$ Perhaps the simplest example of this type of entrant is backward integration by a customer of the incumbent. "Big buyers", can enter secretly by producing for themselves and, having established themselves, then can sell to others in competition with the incumbent.

This is a limited fix, however. If the number of such potential entrants is limited, a big buyer might do better to enter instead into negotiations with the incumbent. The big buyer can credibly threaten to enter, and if it does enter, to drive down the prices the incumbent can charge to other customers. In that case, the incumbent would have the incentive to compensate the buyer to forgo entry, either with a lump sum payment, or perhaps with a long-term supply contract at a low price. ${ }^{60}$ Thus this type of entry is unlikely to maintain competitive prices. ${ }^{61}$

Alternatively, the entry might occur by small entrants practicing

58. See, among others, Spence (1977); Salop (1979); Gelman and Salop (1983); and Stiglitz (1987). Preentry price could affect the rate of entry in models in which price is a signal of the incumbent's costs, market demand, and so on. For example, see Salop (1979); and Milgrom and Roberts (1982).

59. This entrant can succeed, even if it must bear sunk costs. The rationality of the customers might be questioned, however. A customer might do better to wait for the price war than to agree to a long-term contract with the entrant at a potentially higher price.

60. For example, see Katz (1987); Aghion and Bolton (1987); and Scheffman and Spiller (1989). It is interesting that if lump sum payments were not feasible, the buyer could obtain a below-cost supply contract. This is because if the buyer vertically integrates, the incumbent will lose not only potential sales to the buyer but will also suffer price reductions on other sales.

61. The payment to the buyer might be attacked as, in effect, the acquisition of a potential entrant or an agreement that deters entry. But in light of the obvious efficiency defense of a long-term supply contract, it might be difficult for the plaintiff to carry the burden in the absence of "hot documents" that clearly explain the intent. 
“ "judo economics," that is, by limiting their capacity. In this case, the incumbent might rather accommodate their entry than cut price enough to take their sales. Unfortunately, although entry occurs in this model, the entry does not fully deter monopolistic price rises, although price rises may be moderated. ${ }^{62}$ Thus it also fails to provide a full justification for the guidelines' approach.

\section{A Practical Approach to Measuring Ease of Entry}

Despite these fundamental problems, the DOJ approach to entry has a certain intuitive appeal. Antitrust policymakers are interested in the extent to which fear of entry would deter postmerger pricing coordination if the proposed merger is permitted. And while the existence of sunk costs fully deters entry when products are homogeneous and marginal costs are constant, relaxing those assumptions would establish some role for potential entry in constraining price increases in the face of a merger-induced cartel or tacit collusion.

This also suggests a "practical' ' approach to measuring ease of entry. The likelihood of entry in response to a SSNIP depends on several factors identified by Bain and Stigler, as refined by modern theory. These factors can be measured and possibly even combined into an index analogous to the HHI. The factors are the following. ${ }^{63}$

- Cost or demand disadvantages. If the potential entrant faces higher costs or must offer a lower price to offset perceived quality disadvantages, either temporarily or permanently, it is less likely to enter. In the extreme, if the entrant's costs are 10 percent above the costs of established firms, entry into a perfectly competitive industry will not occur in response to a 5 percent postmerger price increase. These disadvantages might include patents, scarce resources already tied up by established firms, and consumer loyalty. ${ }^{64}$

- Time to entry. If entry takes a long time, the fear of entry is less likely to deter postmerger price rises. First, the established firms can

62. For example, the existence of such entrants might induce the incumbent to raise prices by less than a SSNIP, say only 4 percent. The magnitude of this moderating influence depends on the rule for allocating customers to the entrant. See Gelman and Salop (1983); and Fudenberg and Tirole (1984).

63. For further details, see Salop (1986).

64. To the extent these disadvantages were not borne by the established firms, they constitute "Stiglerian" barriers to entry. 
earn profits in the interim. Second, entry is less likely to occur because the established firms have ample time to reduce their own prices before the entrant becomes established. ${ }^{65}$

- Sunk costs. Successful entry is not a certain proposition. Entry may fail because the entrant's costs are relatively high, its products prove to be unpopular, the economy enters a serious recession, or the entry sets off a price war. Entry is a financially risky proposition to the extent that entry costs are sunk. As a result, by raising the entrant's financial exposure, sunk costs reduce the likelihood of entry. ${ }^{66}$

-Economies of scale. When there are sunk costs, entry is less likely when there are substantial scale economies for two main reasons. First, a potential entrant may rationally fear that it will be unable to gain enough sales to justify entry, even at the higher, postmerger price. Second, the potential entrant might fear that the increased postentry competition caused by its entry may lead to lower prices, and thus to lower (or negative) profits. ${ }^{67}$

Economies of scale and entrant disadvantages can be combined into a summary index, minimum viable scale (MVS). The MVS is the total sales a hypothetical new entrant would need to achieve in order to earn a sufficient rate of return ("hurdle rate") on invested capital to justify its entry, assuming a postmerger SSNIP of fixed magnitude (for example, 5 percent), and scaled as a percentage of market output. While there is no exact line dividing low from high MVS levels and MVS estimates will be imperfect in practice, it can be a useful aid to entry analysis. If MVS is large, entry is less likely for three reasons. First, the larger MVS is, the more difficult it is for the entrant to achieve this break-even output level, even when it optimistically assumes that its rivals do not cut their prices in response to its entry. Second, the larger the MVS, the less likely accommodation is. Instead, it becomes more likely that rivals will cut their prices in response to entry at that scale. If prices are cut, that will reduce the entrant's margin over variable costs and thus will raise the sales level it must achieve in order to break

65. The ability to enter secretly and/or obtain long-term contracts enters into this analysis as well.

66. If all capital costs are sunk, this factor is equivalent to Bain's concern with the capital costs of entry.

67. Other ancillary factors include demand elasticity, demand growth, and the ratio of variable costs to premerger prices. 
even. These price cuts then further raise the effective MVS. Third, to the extent that capital costs are sunk, the greater the financial exposure is of an entrant that does not achieve MVS.

\section{Entry in the Absence of Pricing Coordination}

As discussed earlier, the DOJ guidelines are built on a fear that mergers might lead to collusive price increases and pricing coordination. Willig and others have been rethinking merger theory and policy in the context of noncollusive and unilateral (that is, noncooperative equilibrium) price increases arising from mergers, especially in the context of differentiated product markets. ${ }^{68}$ In such markets, mergers may lead to higher prices, even assuming that oligopolistic firms continue to choose outputs and prices noncooperatively. Thus the simple IO models underlying this unilateral conduct approach are the noncooperative oligopoly models, most recently the Farrell and Shapiro model, not the collusion models of Stigler or Green and Porter. ${ }^{69}$ This focus on unilateral conduct in oligopoly markets has several important implications for analyzing mergers.

\section{Basic Methodology}

The unilateral conduct approach does not begin with the hypothetical monopolist or cartel that might raise prices a SSNIP but for the fear of entry. ${ }^{70}$ In a noncooperative oligopoly model, for example, there is no pricing coordination to use as a starting point. Entry may occur after the merger from the change in the market structure, as the merger shifts the best-response functions of established firms. The postmerger equilibrium price may be higher, but not because of pricing coordination.

68. The DOJ guidelines briefly raise the issue of unilateral conduct with the "leading firm proviso." But the issue is not pursued in detail and the leading firm proviso is almost always redundant, in the sense that a merger that violates the proviso almost surely also violates the standard $\mathrm{HHI}$ tests.

69. Farrell and Shapiro (1990a); Stigler (1964); and Green and Porter (1984).

70. As discussed above, that methodology flows directly from the collusion theory of the guidelines. After the merger, when the established firms contemplate attempting to coordinate price increases, the fear of entry may deter that pricing coordination and postmerger prices thereby may remain competitive. 
Instead, price increases and entry are equilibrium phenomena and are not under the direct control of established firms. After the merger, the firms do not collectively choose to hold prices down or raise them in response to the likelihood of entry. Entry either occurs or not in the new equilibrium.

This implies a fundamental shift in analyzing entry because it focuses on different conduct. The conduct focus shifts away from postmerger price increases to the merger itself. In the coordinated price approach the question is whether the fear of entry will deter anticompetitive coordinated price increases. In the unilateral conduct approach, the question is whether the fear of entry will deter anticompetitive mergers. ${ }^{71}$ In terms of IO models, the focus shifts from a "limit pricing", model of a dominant firm facing a threat of entry to a Salant, Switzer, and Reynolds type of model of the profitability of anticompetitive mergers. $^{72}$

\section{The SSNIP Test and the Supply of Entry Function}

This approach also represents a fundamental methodological shift because the formal hypothetical monopolist-SSNIP test for "easy", entry no longer follows from first principles. However, although it rejects the initial justification for the SSNIP test, the unilateral conduct approach goes it one better. This approach gives rigorous meaning to the concept of the supply of entry function implicit in the guidelines. As discussed earlier, when there are sunk costs, the preentry price (which is, after the merger, a SSNIP above the premerger price) is irrelevant to the entry decision. But in a unilateral conduct oligopoly model, the supply of entry function is a best-response function, where entry depends on the postentry equilibrium price, not the preentry price.

Thus the unilateral conduct oligopoly model may have entry after the merger, even though there are sunk costs and postentry competition.

71. An analogous shift in focus from the hypothetical monopolist to the allegedly anticompetitive conduct also occurs in defining relevant markets for analyzing exclusionary conduct. The key question there is whether substitution to other products will prevent a firm from gaining market power in the sale of its output by conduct that allegedly raises its rivals' input costs. Thus the relevant market is not analyzed in a vacuum but rather in the context of the allegedly anticompetitive conduct. See Krattenmaker, Lande, and Salop (1987).

72. Salant, Switzer, and Reynolds (1983). 
And the knowledge that such entry will occur in response to a merger can serve to deter anticompetitive mergers. This is the essence of Willig's approach.

\section{Minimum Viable Scale}

Once the formal SSNIP test for entry is rejected, the question of how to measure the supply of entry function arises. In fact, the concept of MVS still is relevant to entry analysis but with a somewhat different interpretation. The MVS measures the break-even output for an entrant given a particular assumed market price. In the standard guidelines model, the assumed market price was a SSNIP above the premerger price. In the noncoordinated conduct model, the MVS for various assumed prices gives information about the supply of entry function. The only difference is that the assumed price is now interpreted as a potential equilibrium price, not as a possible collusive price. Thus it remains a useful proxy.

\section{Sunk Cost Entry versus Supply Substitution}

The unilateral conduct approach also implies a rethinking of the implications of the guidelines' distinction between supply substitution and new entry. In the guidelines, supply substitution is composed of flexible production capacity that can enter the market within one year in response to a SSNIP. It is flexible entry in that it generally does not involve the expenditure of significant sunk costs. New entry is composed of production capacity that will enter the market within two years in response to a SSNIP and generally involves the expenditure of significant sunk costs. In the guidelines, the more flexible supply substitution capacity is considered a more significant constraint on noncompetitive postmerger pricing than is new sunk cost entry, and so leads to a more permissive merger policy.

In his discussion of this distinction, Willig has raised some interesting questions. For example, fear of new capacity entering the market by way of supply substitution may not deter anticompetitive mergers for the simple reason that this capacity already is effectively in the market. In a noncooperative oligopoly model, that capacity has a best-response function and thereby affects equilibrium premerger prices. Premerger 
equilibrium prices are lower because of the existence of this capacity. The merger then reduces the number of independent firms and so the equilibrium price can rise. Thus this supply substitution capacity should not be double counted. In contrast, fear of new sunk cost capacity entering the market by way of new entry may constrain anticompetitive mergers. This sunk cost capacity is not in the market premerger but may enter postmerger in response to higher prices. Thus it can constrain anticompetitive mergers. As a result, Willig notes the apparent paradox that a merger may be permissible when the firms face a new entrant but nonetheless may be impermissible when the established firms face an identical amount of supply substitution capacity.

This result is a bit confusing because it seems to imply paradoxically that a consumer would rather face a market with a new entry potential than a market with identical supply substitution potential. ${ }^{73}$ That implication is not necessary, however. ${ }^{74}$ This is because the premerger equilibrium price in the supply substitution case will be lower than the price in the new entry case. However, the merger dynamics have offsetting effects. In the supply substitution case, the anticompetitive merger will occur and raise postmerger equilibrium prices. In the case of new sunk cost entry, however, the anticompetitive merger will not occur. ${ }^{75}$

73. That is, suppose the two firms have identical production functions, but the supply substitution firm already has sunk its capital costs, whereas the new sunk cost entrant has not.

74. There may, however, be cases in which consumers would prefer to face a market with a new entry potential rather than a market with identical supply substitution capacity. This apparent paradox even arises in a model of a monopolist facing a threat of entry (either new entry or supply substitution). The monopolist's residual demand curve is everywhere higher in the new entry case because the new sunk cost entrant will not enter unless the equilibrium price is high enough to cover its fixed costs. However, this also means that the residual demand curve has regions that are more elastic. As a result, it is possible that the equilibrium price is lower in the new entry case.

75. Indeed, the equilibrium postmerger price in the new entry case will equal the premerger equilibrium price in the supply substitution case. For example, suppose there initially were six firms plus the entrant. In the supply substitution case, the premerger equilibrium would effectively involve a seven-firm industry. But the merger would reduce this to a six-firm industry. In contrast, in the new sunk cost entry case, the initial equilibrium is a six-firm industry. Merger is deterred by the knowledge that new entry will occur in response to the merger. (This is because, if a merger occurred, the postmerger industry would also have six firms, but the merged firms would have less output in the new equilibrium, as in Salant, Switzer, and Reynolds (1983).) Thus prices are the same in both industries, ex post. 


\section{What Remains to Be Done}

While these are very exciting and provocative ideas, obviously far more work is necessary. First, the ideas must be turned into rigorous formal analysis. Second, the ideas and their implications must be further operationalized.

Formalizing the model along the lines suggested by Willig should not be difficult. The Farrell and Shapiro model of mergers and the various models of Bertrand competition with differentiated products already exist. ${ }^{76}$ One must add a new entrant to these models, whereby the new entrant faces a technology with sunk costs, and then the equilibrium must be calculated. Then the incentives for merger among established firms must be analyzed.

Operationalizing the models involves relating the incentives for anticompetitive mergers to various characteristics of the market, the potential merger partners, and the entrants. Further analysis of markets for differentiated brands and customer loyalty will be necessary because those markets are prime candidates for unilateral conduct playing a key role, as Willig points out.

There is no reason to think that the exact HHI categories used for mergers where there is a likelihood of pricing coordination should remain relevant for evaluating mergers in which the competitive fear involves noncoordinated conduct. The DOJ and Federal Trade Commission could review the mergers that have been analyzed in the past decade to better gauge the appropriate HHI categories. Additional work also is needed to refine the analysis of minimum viable scale, possibly to create a standard methodology for use across industries, rather than relying on whatever capital expenditure models are used by the merging parties. It might also involve gauging the magnitude of the MVS and other determinants of entry, perhaps by forming categories, as is currently the case with the $\mathrm{HHI}$.

This is a major research agenda, to be sure. But in the end the synergy between industrial organization economics and antitrust policy will reward us with a better understanding of noncooperative oligopoly conduct and a merger policy that better serves the interests of consumer welfare and economic efficiency. While the newest revisions of the 
guidelines may not be released by June 14, 1991, they should be worth the wait.

Comment by F. M. Scherer: Robert Willig has served BPEA readers a masterly, complex and well-crafted confection-something like Joan Morris's lemon-lime jello, marshmallow, cottage-cheese surprise. A rough weighing suggests that the ingredients constitute 10 percent history (for example, of the merger guidelines), 20 percent not-so-commonsense wisdom, and 70 percent theory, some plucked fresh from the garden. I have no quarrels with the history and wisdom. But for purposes of formulating a public policy toward mergers, the theory is a bit too jello-like for my taste. And there are some important missing ingredients.

One of the many points at which wisdom emerges is Willig's admission, after impressive manipulation of diverse models, that Cournot quantity-setting behavior may not be very applicable in analyzing "real" mergers, especially when product differentiation gives firms direct control over their prices. Willig therefore turns to alternative Bertrand models, which assume that price rather than quantity is the oligopolistic firm's preferred decision variable. We economists love Cournot and Bertrand models because we can have a good bash at them with the powerful tools of calculus. What is stated only subliminally in Willig's exposition, however, is the assumption that in setting its price à la Bertrand, oligopolist A assumes the prices of firms B and C to be fixed and unresponsive to its own decision, just as the Cournot oligopolist assumes the quantities of its rivals to be fixed. We have known at least since Edward Chamberlin published his famous book nearly sixty years ago that these were rather unrealistic assumptions: "The result is the same when sellers adjust their prices instead of their supplies. . . . If each seeks his maximum profit rationally and intelligently, he will realize that when there are only two or a few sellers his own move has a considerable effect upon his competitors, and that this makes it idle to suppose that they will accept without retaliation the losses he forces upon them.",77

Willig motivates his imaginative new choice-axiomatic Bertrand analysis through an example of products with differentiated positions

77. Chamberlin (1950, p. 48). 
in characteristics space. The richest evidence on pricing behavior under such conditions comes from the ready-to-eat breakfast cereals case, in which I was a witness for the Federal Trade Commission. ${ }^{78}$ My analysis revealed that Kellogg's upward price leadership was usually followed by major rivals General Mills and General Foods. One of the case's many frustrations was the failure to have accepted into evidence documents revealing that Kellogg's price analysts made their recommendations assuming that rivals would follow Kellogg's price lead and therefore that market shares would be preserved. This is not Bertrand behavior by a long stretch, but it is the kind of behavior about which merger policy should be very much concerned.

Outside the scope of his formal mathematical modeling, Willig does recognize that the transition from noncooperative to cooperative (read "coordinated') behavior is indeed important for merger analysis. Why then the emphasis on Cournot-Bertrand (that is, "unilateral') models? Largely, I suspect, because the mathematics are neat. Yet as Franklin Fisher has illuminated in the different context of his paper, the formal models suffer not only from unrealism, but from exquisite sensitivity to minor variations in assumptions. For a well-informed merger policy, it would be much more important, I believe, to have good insight into the market structural point at which behavior changes from noncooperative to cooperative than to spin ever more refined theories about the small or ambiguous difference made by marginal changes in structure within the noncooperative realm. If economics must be mathematical, why can it not be like twentieth-century physics rather than seventeenthcentury physics, studying oligopoly as a problem of determining (at best probabilistically) the "energy state", in which an industry resides?

The Cournot and Bertrand models of pre- versus postmerger pricing are important to Willig because they complement his two-pronged theory of merger causation. Mergers are made, he says, because the merger partners expect them to increase profits. Profits increase for either of two reasons: because monopoly power is increased postmerger, and/or because the merger leads to efficiencies. If it is possible to isolate the conditions under which mergers do enhance monopoly power, then the

78. In re Kellogg Company and others, Docket 8883; decision and order to vacate at 99 Federal Trade Commission Reports 16-269 (1982); see also Scherer (1986, pp. 172202); and Schmalensee (1978, pp. 305-27). 
cases in which they do not can be assumed to be those motivated by efficiency increases, and therefore (glossing over the non sequitur) one need not be concerned with the messy problem of assessing efficiencies.

This is far too simple-minded. For one, there are other plausible motives for merger. Prominent among them are informational or expectational asymmetries, for example, when one side of the transaction expects interest rates to rise and another expects them to fall, or when the acquirer believes that it can in fact consolidate monopoly power while the acquired firm's executives and stockholders believe the contrary. Because most mergers are consummated in a cloud of uncertainty, they often confound the expectations upon which they were based. In the famous Jones and Laughlin-Youngstown Steel merger case of 1978, for example, subpoenaed documents revealed the expectation of merger promoters that Youngstown's disruptive price indiscipline would be curbed in J\&L's steady hands. For rather unusual reasons the merger was allowed to go through, but there is no evidence that pricing behavior changed materially as a consequence. Mergers are also made to satisfy managers' empire-building urges. Although in such differently motivated cases it would still be useful to have theory or evidence that pinpointed the price-raising mergers, Willig's clean partition between monopoly-driven mergers and efficiency-driven mergers breaks down.

More important, by stressing a dichotomy of motives for mergers, Willig deftly sidesteps the thorny problem of mergers that enhance both monopoly power and operating efficiency. In a pioneering article, Oliver Williamson showed theoretically that when this occurs, a trade-off is posed, and that as a rule, relatively small unit-cost reductions attributable to merger more than offset the allocative efficiency losses from plausible merger-based price increases. ${ }^{79}$ For instance, with unit demand elasticity, the deadweight losses from merger-induced price increases of 20 percent are offset if unit-cost reductions exceeding 2 percent follow. Although it authorized a formal "efficiencies" defense in its 1984 merger guidelines, the Department of Justice since then has been back-pedaling and attempting to avoid making such trade-offs. I'm not sure why; I suspect it's because the Antitrust Division's staff is good at manipulating economic models but would be like the proverbial city slicker in a cow pasture if it attempted to evaluate the

79. Williamson (1968). 
efficiency of real-world firms' operations. Nevertheless, I will not let Willig escape (shoes unstained?) so lightly.

The issue has been joined squarely in an antitrust case involving the acquisition by Archer-Daniels-Midland (ADM) of the Clinton Corn Products (CCP) Company's assets from Nabisco Brands (later RJR Nabisco). The corn wet milling industry is highly concentrated, and the principal product in question, the sugar substitute high-fructose corn syrup (HFCS), is currently produced in the United States by seven firms. CCP was once the leader and ADM is currently the leader. If HFCS is a relevant market - a disputed point not addressed here-the Justice Department structural guidelines might arguably have been overstepped. I was a witness for ADM in the trial concluded shortly before this conference. Despite the stigma of being tarred an advocate, I raise the efficiency question here because I believe that encouraging efficiency is an important national policy objective, that the deadweight allocative losses attributable to mergers are seldom large, and that if a trade-off is made, the balance will tilt toward merger when substantial efficiencies are achieved. My goal is to have the courts, and ideally the Supreme Court, write into the case law what the Antitrust Division wrote into its 1984 guidelines.

In the preliminary jockeying on how an efficiencies defense should proceed, the Department of Justice urged that efficiencies attributable to superior management be ignored, that efficiencies resulting from capital expenditures be reviewed case-by-case (potentially requiring the tedious consideration of more than one hundred project authorizatons), that cost savings on corn milling co-products (such as gluten feed, corn oil, and caramel) not defined as part of the relevant market be excluded, and that efficiencies be counted only to the extent that they were passed on to consumers in the form of lower prices. ${ }^{80}$ The last of the four limitations, all rejected by the District Court in a pretrial decision on the scope of evidence to be considered, would deny the possibility of a Williamsonian trade-off.

In its defense, Archer-Daniels-Midland demonstrated that following its takeover of CCP, it reduced costs far in excess of what the prior management contemplated, among other things improving worker

80. Department of Justice, motion in limine, filed in United States v. Archer-DanielsMidland Company and others, May 4, 1987. 
productivity at a six-year average rate of 32 percent a year. A proper defense should show not only that efficiencies were attained, but that the acquirer's performance was better than what could have been achieved by alternative acquirers with significantly smaller market shares. The approach taken was to demonstrate through census and survey data that Archer-Daniels-Midland was the industry's low-cost producer, that it had unique technological know-how, and that its efficiency-driven corporate culture was unmatched by rival firms. How this and other efficiencies evidence will be weighed by the courts remains to be seen.

The Clinton Corn Products case was unusual in the sense that seven years had passed from the time of acquisition to the trial date. Thus evidence on actual achievements could be introduced. Cases in which the merger has not yet taken place are both more common and more difficult. To repeat, merger partners often view their future through rose-colored glasses. To deal with this problem, I propose a two-stage approach. At the premerger stage, the merging firms would be required to present detailed, persuasive evidence of their plans for achieving substantial efficiencies and of their unique qualifications for attaining those efficiencies. Having to bear such a burden of proof would force the parties to think hard about their postmerger operating plans-a step that is often skipped, contributing to postmerger indigestion surprises. ${ }^{81}$ If the burden is sustained, the merger would be approved provisionally for a three-year trial period. If at the end of that period the promised efficiencies cannot in fact be shown, the merger would be undone or, if facilities and distribution channels were scrambled, equivalent assets would be divested. There was a time when this would have been impractical, but the institutions for effecting sell-offs and similar corporate restructurings have evolved to such a state that in most cases, appropriate divestiture measures could be implemented if the postmerger efficiencies defense failed.

The Department of Justice is said to be considering further revision of its merger guidelines. I urge it to adopt an efficiencies defense that can and will be taken seriously. Opportunities for achieving efficiency gains are too important to be ignored in a major instrument of antitrust policy.

81. Ravenscraft and Scherer (1987, chaps. 4, 5, 7, and app. B). 
General Discussion: Several participants argued that IO game theoretical models simply would not be accepted by the legal establishment in the antitrust field. Franklin Fisher said that courts were unlikely to base antitrust rulings on theories that showed that without any evidence of communication or collusion, a merger might still lead to price increases based on game equilibrium behavior. Robert Willig disagreed with Fisher, saying that lawyers are always looking for new theories on which to bring and argue cases.

Lawrence White said that the current merger guidelines are a reflection of the fact that they are ultimately a product of an organization (the Antitrust Division of the Department of Justice) that is run by lawyers, not economists. He implied that the reliance on the HerfindahlHirschman Index of concentration (HHI) in the guidelines is because this measure can be easily understood and worked with by noneconomists, while complex IO theories cannot be. Dennis Carlton questioned the current HHI merger guidelines, especially with respect to industries with a dominant firm and a competitive fringe. He said that if a single firm has a 50 percent market share, the industry HHI value will be astronomical - at a level not permitted by the merger guidelines-but, according to the available econometric evidence, such a firm will probably have zero ability to raise prices if there is a competitive fringe.

Michael Katz was concerned with Willig's focus on Cournot and Bertrand models. He said that these models contain unrealistic assumptions and that maybe one should put more emphasis on more refined alternatives. Katz also questioned the distinctions being made between noncooperative "one-shot" games or collusive repeated games. He suggested that a false dichotomy was being made here, and that all firms are probably involved in playing a dynamic supergame.

Carlton emphasized the importance of case studies in examining the potential harm from mergers. He said that performing a detailed industry study to show the past effects of changes in market concentration in a particular industry will shed light on the effects of a planned merger. Carlton also made some points about the way entry and exit are treated in current merger guidelines. On the issue of entry, he said that too much emphasis was placed on the time of entry and not enough on the viability of new entrants - that is, whether or not they would grow into substantial competitors. With respect to exit, he claimed that mergers among multiunit firms have been prevented in declining industries, even. 
though the merger was the only way to prevent exit of some of the efficient plants. He suggested that this was a bad policy.

Carl Shapiro was pleased to see Willig raise the point that entry might occur in an industry after a merger not only as a result of a price rise but also as a result of the structural change alone. He said however that while theory might show this to be a possibility, he suspected the data would show the price level to be the determinant of entry.

Dennis Mueller brought up the issue of efficiency arguments for permitting a merger. While the government might want to accept increased efficiency as an argument for approving a merger, he said, it might also want to consider blocking mergers that would lead to decreased efficiency.

\section{References}

Abreu, Dilip, David Pearce, and Ennio Stacchetti. 1986. “Optimal Cartel Equilibria with Imperfect Monitoring.' Journal of Economic Theory 39 (June):251-69.

Aghion, Phillipe, and Patrick Bolton. 1987. "Contracts as Barriers to Entry." American Economic Review 77 (June):388-401.

Anderson, Simon P., and Andre de Palma. 1990. "The Logit as a Model of Product Differentiation: Further Results and Extensions." Discussion Paper 913. Northwestern University.

Barton, David M., and Roger Sherman. 1984. "The Price and Profit Effects of Horizontal Mergers: A Case Study." Journal of Industrial Economics 33 (December):165-77.

Baumol, William J., John C. Panzar, and Robert T. Willig. 1982. Contestable Markets and the Theory of Industry Structure. Harcourt Brace Jovanovich.

Besanko, D., M. K. Perry, and R. H. Spady. 1991. “The Logit Model of Monopolistic Competition." Journal of Industrial Economics, forthcoming.

Boyer, Kenneth D. 1979. "Industry Boundaries." In Economic Analysis and Antitrust Law, edited by Terry Calvane and John Siegfried. Little, Brown and Co.

Bresnahan, Timothy F. 1989. "Empirical Studies of Industries with Market Power." In Handbook of Industrial Organization, edited by Richard Schmalensee and Robert D. Willig. 2 vols. Amsterdam and New York: North-Holland.

Chamberlin, Edward H. 1950. The Theory of Monopolistic Competition, sixth ed. Harvard University Press.

Cowling, Keith, and Michael Waterson. 1976. "Price-Cost Margins and Market Structure." Economica 43 (August):267-74. 
Dansby, Robert E., and Robert D. Willig. 1979. "'Industry Performance Gradient Indices.” American Economic Review 69 (June):249-60.

Deneckere, Raymond, and Carl Davidson. 1985. "Incentives to Form Coalitions with Bertrand Competition."' Rand Journal of Economics 16 (Winter):473-86.

Deneckere, Raymond J., and Dan Kovenock. 1989. "Capacity-Constrained Price Competition When Unit Costs Differ.' CMSEMS Discussion Paper 861. Northwestern University.

Dixit, Avinash K. 1982. "Comparative Statics for Oligopoly." International Economic Review 27 (February): 107-22.

Eaton, B. Curtis, and Richard G. Lipsey. 1989. "Product Differentiation." In Handbook of Industrial Organization, edited by Richard Schmalensee and Robert D. Willig. 2 vols. Amsterdam and New York: North-Holland.

Farrell, Joseph, and Carl Shapiro. 1990a. "Horizontal Mergers: An Equilibrium Analysis." American Economic Review 80 (March):107-26.

- 1990b. "Asset Ownership and Market Structure in Oligopoly." Rand Journal of Economics 21 (Summer):275-92.

Friedman, James W. 1977. Oligopoly and the Theory of Games. Amsterdam: North-Holland.

Fudenberg, Drew, and Jean Tirole. 1984. "The Fat Cat Effect, the Puppy Dog Ploy, and the Lean and Hungry Look." American Economic Review, Papers and Proceedings, 74 (May):361-66.

Gelman, Judith R., and Steven C. Salop. 1983. "Judo Economics: Capacity Limitation and Coupon Competition." Bell Journal of Economics 14 (Autumn):315-325.

Gilbert, Richard. 1989. "Mobility Barriers and the Value of Incumbency." In Handbook of Industrial Organization, edited by Richard Schmalensee and Robert D. Willig. 2 vols. Amsterdam and New York: North-Holland.

Green, Edward J., and Robert H. Porter. 1984. "Non-Cooperative Collusion under Imperfect Price Information.” Econometrica 52 (January):87-100.

Herk, Leonard F. 1990. "Consumer Self-Selection and the Cournot Solution in a Duopoly Model of Capacity and Price Competition.” Mimeo, Johns Hopkins University.

Hurdle, Gloria J., and others. 1989. "Concentration, Potential Entry, and Performance in the Airline Industry." Journal of Industrial Economics 38 (December):119-39.

Jacquemin, Alexis, and Margaret E. Slade. 1989. “'Cartels, Collusion, and Horizontal Merger." In Handbook of Industrial Organization, edited by Richard Schmalensee and Robert D. Willig. Amsterdam and New York: North-Holland.

Katz, Michael. 1987. "The Welfare Effects of Third Degree Price Discrimination in Intermediate Goods Markets. American Economic Review 77 (March):15467. 
Kessides, Ioannis N. 1986. "Advertising, Sunk Costs, and Barriers to Entry." Review of Economics and Statistics 68 (February):84-95.

Krattenmaker, Thomas G., Robert G. Lande, and Steven C. Salop. 1987. “Monopoly Power and Market Power in Antitrust Law." Georgetown University Law Journal 76 (December):241-69.

Kreps, David M., and Jose A. Scheinkman. 1983. "Cournot Precommitment and Bertrand Competition Yield Cournot Outcomes." Bell Journal of Economics 14 (Autumn):326-37.

Luce, R. Duncan. 1959. Individual Choice Behavior: Theoretical Analysis. John Wiley and Sons.

McFadden, Daniel. 1973. "Conditional Logit Analysis of Qualitative Choice Behavior." In Frontiers in Econometrics, edited by Paul Zarembka. Academic Press.

Milgrom, Paul, and John Roberts. 1982. "Limit Pricing and Entry under Incomplete Information." Econometrica 50 (March):443-60.

Ordover, Janusz A., A. Sykes, and Robert D. Willig. 1982. "Herfindahl Concentration, Rivalry and Mergers."' Harvard Law Review 95 (June):1857.

Ordover, Janusz A., and Robert D. Willig. 1983. "The 1982 Department of Justice Merger Guidelines: An Economic Assessment." California Law Review 71 (March):535-74.

_ 1985. "Antitrust for High-Technology Industries: Assessing Research Joint Ventures and Mergers." Journal of Law and Economics (May):311-33.

Perloff, Jeffrey, and Steven C. Salop. 1985. "Equilibrium with Product Differentiation." Review of Economic Studies 52 (January):107-20.

Perry, Martin K., and Robert H. Porter. 1985. "Oligopoly and the Incentive for Horizontal Merger." American Economic Review 75 (March):219-27.

Porter, Robert H. 1983. "Optimal Cartel Trigger Price Strategies." Journal of Economic Theory 29 (April):313-38.

Ravenscraft, David J., and F. M. Scherer. 1987. Mergers, Sell-offs, and Economic Efficiency. Brookings.

Rill, James F. 1990a. “'Merger Enforcement at the Department of Justice." Paper presented before the American Bar Association (March).

- 1990b. "Antitrust Enforcement at the Department of Justice." New England Antitrust Conference (November).

Salant, Steven, Sheldon Switzer, and Robert J. Reynolds. 1983. "Losses from Horizontal Merger: The Effects of an Exogenous Change in Industry Structure on Cournot-Nash Equilibrium." Quarterly Journal of Economics 48 (May):185-99.

Salop, Steven C.. 1979. "Strategic Entry Deterrence." American Economic Review, Papers and Proceedings 69 (May):335-38. 70.

Salop Steven C., and others. 1987. "Symposium on Horizontal Mergers and Antitrust."' Journal of Economic Perspectives 1 (Fall):3-54. 
Scheffman, David T., and Pablo Spiller. 1991. "Buyer's Strategies, Entry Barriers, and Competition. Economic Inquiry," forthcoming.

Scherer, F. M. 1980. Industrial Market Structure and Economic Performance, $2 \mathrm{~d}$ ed. Houghton Mifflin.

_ 1986. “The Breakrfast Cereal Industry."' In The Structure of American Industry, seventh ed., edited by Walter Adams. Macmillan.

Schmalensee, Richard. 1978. "Entry Deterence in the Ready-to-Eat Breakfast Cereals Industry." Bell Journal of Economics 9 (Autumn):305-27.

. 1989. "Inter-Industry Studies of Structure and Performance." In Handbook of Industrial Organization, edited by Richard Schmalensee and Robert D. Willig. 2 vols. Amsterdam and New York: North-Holland.

Schumann, L., R. Rogers, and J. Reitzes. 1990. "Case Studies of the Price Effects of Horizontal Mergers." Paper presented at the meeting of the Southern Economic Association.

Shapiro, Carl. 1989. "Theories of Oligopoly Behavior." In Handbook of Industrial Organization, edited by Richard Schmalensee and Robert D. Willig. 2 vols. Amsterdam and New York: North-Holland.

Spence, A. 1977. "Entry, Capacity, Investment, and Oligopolistic Pricing. Bell Journal of Economics 8 (Autumn):534-44.

Stigler, George J. 1964. “The Theory of Oligopoly." Journal of Political Economy 72 (February):44-61.

Stiglitz, Joseph E. 1987. "Technological Change, Sunk Costs, and Competition, Brookings Papers on Economic Activity (Special Issue on Microeconomics): 883-947.

Tirole, Jean. 1988. The Theory of Industrial Organization. MIT Press.

U.S. Department of Justice. 1984. Merger Guidelines. Reprinted in Commerce Clearinghouse. 1984. Trade Regulation Reports. \13, 103.

Werden, Gregory J. 1983. "Market Delineation and the Justice Department's Merger Guidelines.” Duke Law Journal 3 (June):514-79.

- 1990. "Antitrust Policy toward Horizontal Mergers: A Comment on Farrell and Shapiro." Economic Analysis Group Discussion Paper 90-4 (May 15, 1990). American Economic Review, forthcoming.

Werden, Gregory J., Andrew S. Joskow, and Richard L. Johnson. 1991. "The Effects of Mergers on Price and Output: Two Case Studies from the Airline Industry." Managerial and Decision Economics, forthoming.

Williamson, Oliver E. 1968. "Economies as an Antitrust Defense: The Welfare Tradeoffs." American Economic Review 58 (March):18-36.

California Law Review 71 (March):604-00. 